Paper published in:

F. D’Onza, D. Gallipoli, S. Wheeler, F. Casini, J. Vaunat, N. Khalili, L. Laloui, C.

Mancuso, D. Masin, M. Nuth, J. M. Pereira, R. Vassallo (2011). Benchmark of constitutive models for unsaturated soils. Géotechnique 61(4): 285-304 -

http://dx.doi.org/10.1680/geot.2011.61.4.283

\title{
BENCHMARK OF CONSTITUTIVE MODELS FOR UNSATURATED SOILS
}

Francesca D’Onza ${ }^{1}$, Domenico Gallipoli ${ }^{2}$, Simon Wheeler ${ }^{3}$, Francesca Casini ${ }^{4}$, Jean Vaunat $^{5}$, Nasser Khalili ${ }^{6}$, Lyesse Laloui ${ }^{7}$, Claudio Mancuso ${ }^{8}$, David Mašín ${ }^{9}$, Mathieu Nuth $^{10}$, Jean Michel Pereira ${ }^{11}$, Roberto Vassallo ${ }^{12}$

1 "Marie Curie" Intra-European Fellow, School of Engineering, University of Glasgow, Glasgow, United Kingdom, email: francesca.donza@glasgow.ac.uk

2 Reader, School of Engineering, University of Glasgow, Glasgow, United Kingdom, email: domenico.gallipoli@glasgow.ac.uk

3 Professor, School of Engineering, University of Glasgow, Glasgow, United Kingdom, email: simon.wheeler@glasgow.ac.uk

4 Postdoctoral Researcher, Institute for Geotechnical Engineering, ETHZ, Zurich, Switzerland (formerly Departamento de Ingeniería del Terreno, Cartográfica y Geofísica, Universitat Politècnica de Catalunya, Barcelona, Spain), email: francesca.casini@igt.baug.ethz.ch

5 Senior Lecturer, Departamento de Ingeniería del Terreno, Cartográfica y Geofísica, Universitat Politècnica de Catalunya, Barcelona, Spain, email: jean.vaunat@upc.edu

6 Professor, School of Civil and Environmental Engineering, University of New South Wales, Sydney, Australia, email: n.khalili@unsw.edu.au

7 Professor, Soil Mechanics Laboratory, École Polytechnique Fédérale de Lausanne, Lausanne, Switzerland, email: Iyesse.laloui@epfl.ch

8 Professor, Dipartimento di Ingegneria Idraulica, Geotecnica ed Ambientale, Università di Napoli Federico II, Napoli, Italy, email: mancuso@unina.it

9 Senior Lecturer, Faculty of Science, Charles University, Prague, Czech Republic, email: masin@natur.cuni.cz

10 Postdoctoral Researcher, Soil Mechanics Laboratory, École Polytechnique Fédérale de Lausanne, Lausanne, Switzerland, email: mathieu.nuth@epfl.ch

${ }^{11}$ Lecturer, Université Paris-Est, Navier - Cermes, Ecole des Ponts ParisTech, Marne-laVallée, France, email: jeanmichel.pereira@enpc.fr

12 Lecturer, Dipartimento di Strutture, Geotecnica, Geologia Applicata, Università della Basilicata, Italy, email: roberto.vassallo@unibas.it

NUMBER OF WORDS: 9654

NUMBER OF TABLES: 4

NUMBER OF FIGURES: 13 
ABSTRACT: The paper presents a collaborative piece of research undertaken by seven research teams from different universities within the MUSE network. The objective is to benchmark different approaches to constitutive modelling of mechanical and water retention behaviour of unsaturated soils by comparing simulations of suction controlled and constant water content laboratory tests.

A set of thirteen triaxial and oedometer laboratory tests, covering the mechanical and water retention behaviour of an unsaturated compacted silty soil under a variety of stress paths, has been provided by one of the seven participating teams. This data set has been used by the other six teams for calibrating a constitutive model of their choice, which has been subsequently employed for predicting strains and degree of saturation in three of the thirteen tests used for calibration as well as in one "blind" test for which experimental results had not been previously disclosed.

By comparing predictions from all teams among themselves and against experimental data, the work highlights the capability of some of the current modelling approaches to reproduce specific features of the mechanical and water retention behaviour of unsaturated soils helping to identify potential areas of weakness where future research should focus. It also demonstrates the dispersion of results to be expected when different constitutive models, independently calibrated by different teams of researchers, are used to predict soil behaviour along the same stress path.

KEYWORDS: constitutive relations, laboratory tests, partial saturation, plasticity, suction 


\section{INTRODUCTION}

This paper presents a collaborative piece of research undertaken by seven universities to benchmark different mechanical and water retention soil models. The objective is to demonstrate the variability of predictions typically obtained when the soil response along a given hydro-mechanical stress path is independently simulated by different researchers using different constitutive models, albeit calibrated from a single set of experimental data. From an engineering perspective, this provides an indication of the discrepancies of predicted behaviour that can potentially occur in geotechnical design as a result of both the choice of constitutive model and the subsequent calibration on the basis of suction-controlled laboratory data.

The benchmarking exercise took place in the framework of a wider scientific programme carried out between 2004 and 2008 by the MUSE (Mechanics of Unsaturated Soils for Engineering) "Marie Curie" Research Training Network with the financial support of the European Commission. It involved seven teams of researchers at different universities, namely the Universitat Politecnica de Catalunya (UPC) in Spain, the University of Glasgow (UGLAS) in the United Kingdom, the University of Naples Federico II (UNINA) in Italy, the Ecole Nationale des Ponts et

Chaussées (ENPC) in France, the École Polytechnique Fédérale de Lausanne (EPFL) in Switzerland, the University of New South Wales (UNSW) in Australia and Charles University (CU) in the Czech Republic.

At the start of the exercise, UPC provided the other six teams with results from a set of thirteen laboratory tests on compacted silt published in the $\mathrm{PhD}$ thesis of Casini (Casini, 2008). The six teams then chose a constitutive model, calibrated the relevant 
parameter values on the basis of the laboratory data provided and predicted the deformation as well as the water retention behaviour during three of the thirteen calibration tests plus one blind test for which experimental results had not been published.

The exercise was coordinated by UGLAS, which circulated spreadsheets with laboratory test results together with an accompanying document containing additional soil data and a description of the sample preparation procedure. The six teams of constitutive modellers were asked to refrain from looking at additional information contained in the $\mathrm{PhD}$ thesis of Casini (Casini, 2008) or related publications. Standard return forms were also circulated for completion by each team with their predictions. Teams also had to provide the list of parameter values used in their simulations, together with a brief description of the procedure followed during calibration of their chosen model.

Readers interested in replicating this benchmarking exercise by using a constitutive model of their choice can download electronic copies of the specification document, return forms and experimental data spreadsheets from the MUSE website (http://muse.dur.ac.uk/) or, alternatively, contact one of the authors to obtain copies of the relevant documentation.

\section{CONSTITUTIVE MODELS}

Seven constitutive models have been considered, one for each team with exception of UGLAS that returned predictions from two models (see Table 1). Hereafter, the theoretical bases of the different constitutive frameworks are compared with reference 
to the water retention behaviour, stress tensor definition, effect of suction on mechanical behaviour and nature of irreversible deformation. For the detailed formulation of each model, the reader is invited to refer to the original articles listed in Table 1.

\section{Water retention models}

All water retention models assume a relationship between degree of saturation $S_{r}$ and suction $s=u_{a}-u_{w}$ (where $u_{a}$ and $u_{w}$ are the pore air and pore water pressures respectively) that depends on volumetric strain, by predicting a shift of the $S_{r}-s$ curve towards the higher suction range as porosity decreases.

Models are divided into two primary groups depending on whether hydraulic hysteresis is neglected (CU, ENPC, UGLAS-1, UGLAS-2 and UNINA) or accounted for (EPFL and UNSW). In the former group, irreversible changes of degree of saturation during wetting-drying cycles are caused by irreversible volumetric strains alone whereas, in the latter group, they are attributable to both plastic volumetric strains and water retention hysteresis.

The five models of the first primary group are further sub-divided into two categories depending on the form of the relationship linking degree of saturation, suction and changes in pore volume. In the first category, UGLAS-1, UGLAS-2 and UNINA adopt the Van Genuchten water retention curve (Van Genuchten, 1980):

$S_{r}=\left(1+(\alpha s)^{n}\right)^{-m}$ 
where $m$ and $n$ are model parameter. The effect of soil deformability is introduced by expressing parameter $\alpha$ (related to the air entry suction) as a power function of void ratio following the Gallipoli, Wheeler and Karstunen water retention model (Gallipoli et al., 2003).

In the second category, the ENPC and CU models adopt the Brooks and Corey water retention curve (Brooks and Corey, 1964):

$S_{r}=\left(\frac{s}{s_{e}}\right)^{-\lambda} \Rightarrow \log S_{r}=-\lambda \log \frac{s}{s_{e}}$

described by a line in the $\log S_{r}$-log $s$ plane with slope $\lambda$ and intercept $s_{e}$ (the latter coinciding with the air entry suction). The effect of soil deformability is introduced by expressing the slope $\lambda$ and air entry suction $s_{e}$ as functions of porosity according to different mathematical formulations in the two models.

In the second primary group, the EPFL and UNSW models assume a "main" hysteretic loop, described by a main drying and a main wetting curve, which bounds the region of attainable values for degree of saturation and suction. The major difference between these two models lies in the definition of the main curves, which are parallel straight lines in the $\log S_{r}$-log $s$ plane for UNSW (i.e. lines described by equation (2) with $s_{e}$ equal to either the air entry or air expulsion suction depending on whether a main drying or wetting line is considered) and parallel straight lines in the $S_{r}-\log s$ plane for EPFL. A family of scanning lines of fixed slope spans the distance between the two main curves to simulate suction reversals starting from main wetting or main drying conditions. In both models, volumetric strains produce a rigid translation of the main hysteretic loop along the suction axis, i.e. a translation that 
keeps the slope and the relative distance of the main lines constant. A residual value of degree of saturation is also introduced as a lower limit when suction grows large.

\section{Definition of constitutive stress tensor}

Depending on the model considered, the constitutive stress tensor $\boldsymbol{\sigma}^{\prime}$ is differently defined as a function of net stress $\boldsymbol{\sigma}=\boldsymbol{\sigma}_{t o t}-u_{a} \cdot \mathbf{1}$ (where $\boldsymbol{\sigma}_{t o t}$ is the total stress tensor and $u_{a} \cdot \mathbf{1}$ is the isotropic tensor of pore air pressure), suction $s$ and degree of saturation $S_{r}$

The following general definition of the constitutive stress tensor is introduced to help distinguishing between different formulations:

$\boldsymbol{\sigma}^{\prime}=\boldsymbol{\sigma}+\chi_{1} \cdot s \cdot \mathbf{1}+\chi_{2} \cdot \mathbf{1}$

where $\chi_{1}$ is a factor between zero and one weighing the effect of suction on the solid skeleton and $\chi_{2}$ is an additive term measuring energy changes in the phase interfaces (Coussy and Dangla, 2002).

Gens (Gens, 1996) defined three classes of constitutive stresses depending on whether (i) $\chi_{I}=0$, (ii) $\chi_{I}=\chi_{I}(s)$ depends on suction but not degree of saturation for $s>s_{e}$ (with $\chi_{l}=1$ for $s \leq s_{e}$ ) or (iii) $\chi_{l}=\chi_{l}\left(S_{r}\right)$ depends on degree of saturation and possibly suction (with $\chi_{l}=1$ for $S_{r}=1$ ). However, Gens (Gens, 1996) did not consider the additive term $\chi_{2}$ measuring energy changes in the phase interfaces in equation (3), and his classification is here expanded to introduce a fourth class of constitutive stresses to contemplate this extra case. 
Both second and third classes define the constitutive stress as the sum of the net stress tensor plus the product of the isotropic suction tensor multiplied by a scalar coefficient varying between zero and one. A constitutive stress of the third class can therefore be recast into a constitutive stress of the second class (and vice versa a constitutive stress of the second class can be recast into a constitutive stress of the third class) by using the chosen water retention model to relate degree of saturation to suction. Of course, this water retention model can also incorporate a dependency of the relationship between degree of saturation and suction on volumetric strains and/or hydraulic hysteresis as relevant. In spite of such similarities, the distinction between second and third class of constitutive stresses is retained in this work, consistent with the proposal by Gens (Gens, 1996), because this allows to distinguish between formulations depending on the "parent" definition of constitutive stress from which multiple "child" definitions of constitutive stress of another class can be obtained by combination with different water retention relationships.

The UGLAS-1, UGLAS-2 and UNINA models are formulated in terms of the net stress tensor, hence they fall in the first class for which $\chi_{1}=0$ and $\chi_{2}=0$.

The CU and UNSW models adopt a constitutive stress of the second class for which $\chi_{1}$ depends on suction for $s>s_{e}$ while $\chi_{2}=0$. In the $\mathrm{CU}$ model the factor $\chi_{1}$ is expressed as:

$$
\chi_{1}=\left(\frac{s}{s_{e}}\right)^{-\gamma}
$$

where $\gamma$ is a model parameter (Khalili and Khabbaz, 1998) whereas, in the UNSW model, $\chi_{1}$ varies according to a hysteretic law similar to the water retention model 
defined by a pair of main drying and main wetting lines of constant slope in the log $\chi_{1}-\log s$ plane having the form of equation (4). Scanning lines of fixed slope describe the variation of $\chi_{1}$ during suction reversals starting from main wetting or main drying conditions.

Due to the particular choice of water retention relationship in the CU model, the primary constitutive stress can be recast in an alternative form consistent with the third class by combining equation (2) with equation (4) to yield:

$$
\chi_{1}=S_{r}^{\frac{\gamma}{\lambda}}
$$

The same is true for the constitutive stress adopted by UNSW if the soil state belongs to a main drying or main wetting curve.

The EPFL model is formulated in terms of a constitutive stress of the third class and assumes $\chi_{1}=S_{r}$ while $\chi_{2}=0$.

Finally, the ENPC model is formulated in terms of a constitutive stress of the fourth class with $\chi_{1}=S_{r}$ while $\chi_{2}$ provides a measure of the energy change in the phase interfaces through the following integral:

$$
\chi_{2}=\frac{2}{3} \int_{S_{r}}^{1} s\left(S_{r}\right) d S_{r}
$$

where $s\left(S_{r}\right)$ is the inverse of the assumed water retention curve (Coussy and Dangla, 2002; Dangla, 2002).

Models adopting a constitutive stress tensor of the first class incorporate a suctioninduced cohesive term into their critical strength equation while models adopting a 
constitutive stress tensor of second, third and fourth classes predict critical strength by means of a purely frictional law with no suction-induced cohesive term. In addition, if a constitutive stress of the second, third or fourth class is employed, there is no need for an independent relationship linking elastic strains to suction.

\section{Effect of suction on mechanical behaviour}

All models incorporate suction as a scalar constitutive variable in addition to the constitutive stress tensor. The ENPC, EPFL, UGLAS-1, UGLAS-2, UNINA and UNSW models adopt an elasto-plastic formulation where suction defines the expansion of the yield or bounding surface together with the spacing and slope of the constant-suction normal compression lines. The CU model adopts a hypoplastic formulation, where no distinction is made between elastic and plastic strains, but suction is still included in a similar manner by controlling the size of the bounding surface through the Hvorslev equivalent stress. For the sake of simplicity, the term "yield" is used in the following to indicate stress states corresponding to the onset of irreversible deformations in classical plasticity models as well as stress states corresponding to bounding conditions in bounding surface plasticity or hypoplastic models.

An increase of suction has a similar effect in all models producing an increase of the mean yield constitutive stress in the absence of irreversible strains. This increase of mean yield constitutive stress corresponds to an expansion of the yield surface in the stress space. In the CU, ENPC, EPFL and UNSW models, this expansion is homologous in the $q-p^{\prime}$ plane ( $p^{\prime}$ is the mean constitutive stress and $q$ is the deviator stress) at constant Lode angle with the centre of homology coinciding with the origin. 
Note that, in the elasto-plastic formulations by EPFL and UNSW, suction is introduced as a hardening parameter rather than a stress variable. Nevertheless, in order to simplify terminology and given that the practical effects of suction are similar in all models, the expression "yield curve" is generally used in the following to denote the variation of yield stress in the $s-p^{\prime}$ plane, regardless of whether suction is introduced as a stress variable or a hardening parameter.

Models are here distinguished according to the form of the yield curve in the $s-p^{\prime}$ plane for $s>s_{e}$. A classification applicable to all models, regardless of the type of constitutive stress adopted, is introduced based on the following general expression of yield curve in the $s-p^{\prime}$ plane:

$p_{0}^{\prime}(s)=\omega_{1} \cdot p_{0}^{\prime}\left(s_{e}\right)^{\omega_{2}}+\omega_{3}$

In equation (7), $p_{0}^{\prime}(s)$ is the mean yield constitutive stress for $s>s_{e}$ and $p_{0}^{\prime}\left(s_{e}\right)$ is the mean yield constitutive stress at $s=s_{e}$, which coincides with the volumetric hardening parameter in the elasto-plastic models. For $s \leq s_{e}$, the mean yield constitutive stress $p_{0}^{\prime}(s)$ is calculated from the principle of effective stresses for saturated soils taking into account the definition of constitutive stress. The three symbols $\omega_{1}, \omega_{2}$ and $\omega_{3}$ denote three functions of suction governing the increase of mean yield constitutive stress with increasing suction.

Three classes of models are thus defined according to the following three cases: (a) $\omega_{1}=\omega_{1}(s)$ is a function of suction (with $\omega_{1}=1$ when $s=s_{e}$ ) while $\omega_{2}=1$ and $\omega_{3}=0$ are both constant, (b) $\omega_{1}=\omega_{1}(s)$ and $\omega_{2}=\omega_{2}(s)$ are both functions of suction (with $\omega_{1}=1$ 
and $\omega_{2}=1$ when $\left.s=s_{e}\right)$ while $\omega_{3}=0$ is constant and (c) $\omega_{1}=\omega_{1}(s)$ and $\omega_{3}=\omega_{3}(s)$ are both functions of suction (with $\omega_{1}=1$ and $\omega_{3}=0$ when $s=s_{e}$ ) while $\omega_{2}=1$ is constant.

If the saturated normal compression line and the volumetric elastic law are given, the choice of one of the above three classes of yield curve implicitly fixes the form of the constant-suction normal compression lines. If the saturated normal compression line and the elastic compression law are both represented by straight lines in the $v-\ln p^{\prime}$ plane (where $v$ is the specific volume and $p^{\prime}$ is the mean constitutive stress), a yield curve of the first class corresponds to a family of parallel straight constant-suction normal compression lines, a yield curve of the second class corresponds to a family of straight constant-suction normal compression lines of variable slopes and a yield curve of the third class corresponds to a family of curved constant-suction normal compression lines (see Appendix for a proof). In the Appendix it is shown that the slope and spacing of constant-suction normal compression lines are governed by the functions $\omega_{1}=\omega_{1}(s)$ and $\omega_{2}=\omega_{2}(s)$, respectively.

The EPFL and UNSW models adopt yield curves of the first class. The CU, UGLAS1, UGLAS-2 and UNINA models adopt yield curves of the second class (with $s_{e}=0$ for UGLAS-1, UGLAS-2 and UNINA). Note, however, that the particular model calibration by UNINA produces parallel constant-suction normal compression lines in the $v-\ln p^{\prime}$ plane and thus $\omega_{2}=1$ (see equation (A8)), which changes the class of yield curve from second to first. Finally, the ENPC model assumes a yield curve of the third class, though again the particular model calibration by ENPC implies $\omega_{3}=0$, which changes the class of yield curve from third to first. 
In the second class, the CU, UGLAS-1 and UGLAS-2 models assume that the functions $\omega_{1}=\omega_{1}(s)$ and $\omega_{2}=\omega_{2}(s)$ are related through an exponential law as:

$\omega_{1}(s)=p_{r e f}^{\left(1-\omega_{2}(s)\right)}$

where $p_{\text {ref }}$ is a reference pressure such that the yield curve reduces to a straight vertical line in the $s-p^{\prime}$ plane when $p_{0}^{\prime}\left(s_{e}\right)=p_{r e f}$, as shown by combining equations (7) and (8).

A classification matrix of the different models, according to the type of constitutive stress tensor and yield curve, is given in Table 2 .

\section{Irreversible mechanical behaviour}

A first distinction can be made depending on the way irreversible mechanical behaviour is incorporated in the different formulations. In the ENPC, EPFL, UGLAS1, UGLAS-2, UNINA and UNSW models, irreversibility of strains is introduced by making use of standard elasto-plastic principles. The CU model is instead formulated in the context of the hypoplasticity theory, which does not distinguish between elastic and plastic strains but describes irreversible behaviour by means of an incrementally non-linear stress-strain relationship, where material stiffness depends on both stress state and direction of strain vector. Though being algebraically different, the CU model is based on critical state soil mechanics similarly to the other models (Gudehus and Mašín, 2009) and incorporates the so-called swept-out-memory surface (Mašín and Herle, 2005) as an alternative to the yield surface of elasto-plastic models. 
A second distinction can be made between models that account for anisotropy of irreversible strains (ENPC, EPFL, UGLAS-2, UNINA and UNSW) and models that do not (CU and UGLAS-1).

Among anisotropic models, two groups are distinguished depending on whether anisotropy of plastic strains but not anisotropy of yielding and plastic hardening is taken into account or, alternatively, anisotropy of plastic strains, yielding and plastic hardening are all considered.

The former group, which includes EPFL, UNINA and UNSW, assume constantsuction yield surfaces aligned with the hydrostatic axis in the principal stress space, whose evolution is governed by volumetric but not rotational hardening. Yielding and plastic hardening therefore depend only on the magnitude of the three principal stresses but not on their orientation with respect to the external reference system. Anisotropy of plastic strains is accounted for by introducing a non associative flow rule that predicts irreversible shear strain during mechanical loading or wetting on the hydrostatic axis.

The latter group of models, including ENPC and UGLAS-2, adopt constant-suction yield surfaces which are aligned at an angle with the hydrostatic axis in the principal stress space and whose evolution is governed by both volumetric and rotational hardening. In this case, yielding and plastic hardening depend on the value of the three principal stresses as well as on their orientation with respect to the external reference system. Given the inclination of the yield surface, both associative (as in the 
UGLAS-2 model) and non associative flow rules (as in the ENPC model) can predict anisotropic plastic strains during loading or wetting on the hydrostatic axis.

Among the isotropic models, CU and UGLAS-1 assume constant-suction yield surfaces aligned along the hydrostatic axis, with isotropic irreversible strains predicted during plastic loading or wetting on the hydrostatic axis. In particular, the UGLAS-1 model adopts a non associative flow rule with no shear component for stress states on the hydrostatic axis.

Models can also be classified depending on whether a smooth or sharp transition between elastic and plastic behaviour is predicted. CU and UNSW adopt models of the first type based on a hypoplastic formulation in the case of CU and bounding surface plasticity in the case of UNSW. Both these models predict a gradual build up of irreversible strains and show continuous derivatives of the stress-strain curve during monotonic loading. On the other hand, ENPC, EPFL, UGLAS-1, UGLAS2 and UNINA adopt models of the second type, which result in a discontinuity of the derivative of the stress-strain curve at the onset of yielding (though, in the case of EPFL, a different choice of model parameters can also produce a smooth response consistent with the behaviour of the first group of models).

\section{EXPERIMENTAL DATA SET}

Experimental data were obtained from suction-controlled triaxial and oedometer tests on compacted samples of Jossigny silt (Casini, 2008). Figure 1 shows the grading curve of this soil, which includes $5 \%$ sand, $70 \%$ silt and $25 \%$ clay. The specific 
gravity is equal to 2.69 with a liquid limit of $32 \%$ and a plastic limit of $17 \%$, which classifies the soil as silty clay of low plasticity according to the USCS.

Loose soil was initially mixed to a target water content of $13 \%$. By assuming that the water content of the wet mixture was equal to the target value, an appropriate mass of soil was compacted in layers by one-dimensional static compression to achieve a target dry unit weight of $14.5 \mathrm{kN} / \mathrm{m}^{3}$. Triaxial samples of $7 \mathrm{~cm}$ diameter were compacted in four layers to a height of $14 \mathrm{~cm}$, while oedometer samples of $5 \mathrm{~cm}$ diameter were compacted in a single layer to a height of $2 \mathrm{~cm}$. This required the application of pressures ranging from $150 \mathrm{kPa}$ to $200 \mathrm{kPa}$ for each layer. No measurement of suction was performed after compaction.

It was subsequently noticed that water content during compaction was in some cases slightly different from the target value, which caused a variation of the postcompaction values of void ratio and degree of saturation among samples.

\section{Calibration tests}

The data set circulated for calibration of the different models included the following 13 tests (here identified by using the same codes as in the PhD thesis of Casini (Casini, 2008)):

- 4 compression tests performed in triaxial cells at constant suction of $200 \mathrm{kPa}$. Of these, 1 test involved isotropic loading (TX03) and 3 tests involved anisotropic loading (TX04, TX08 and TX09). 
- 4 compression tests followed by shearing performed in triaxial cells at constant suction of $200 \mathrm{kPa}$. Of these, 1 test involved isotropic loading prior to shearing (TX02), 2 tests involved anisotropic loading prior to shearing (TX06 and TX07) and 1 test involved no loading prior to shearing (TX01).

- 5 Ko-compression tests (EDO-sat, EDO-10, EDO-50, EDO-100 and EDO200) performed in an oedometer under saturated conditions and at constant suctions of $10 \mathrm{kPa}, 50 \mathrm{kPa}, 100 \mathrm{kPa}$ and $200 \mathrm{kPa}$, respectively. All tests followed loading-unloading-reloading paths at constant suction. In addition, the test at a suction of $200 \mathrm{kPa}$ included two wetting drying cycles, before loading and after reloading, under a constant vertical net stress.

All tests are summarized in Table 3, which also lists the post-compaction values of void ratio and degree of saturation, together with the net stress and suction imposed during initial equalization prior to the start of the test. Note that, in Table $3, p$ denotes the mean net stress (which is in general different from the mean constitutive stress $p^{\prime}$ ), $\sigma_{v}$ denotes the vertical net stress (which is in general different from the vertical constitutive stress $\left.\sigma_{v}{ }^{\prime}\right), u_{a}$ denotes the pore air pressure and $\eta$ denotes the ratio between the increments of deviator and mean net stress during loading.

The stress paths for the tests carried out in the triaxial cells (TX01, TX02, TX03, TX04, TX06, TX07, TX08 and TX09) are shown in Figure 2 (tests with loading only) and Figure 3 (tests with loading followed by shearing). All loading stages were performed by ramping radial net stress at a constant rate of $5 \mathrm{kPa} /$ hour while the shearing stages were performed by imposing a constant axial compression rate of 0.2 $\mathrm{mm} /$ hour. The stress paths for the tests carried out in the oedometer cells (EDO-sat, 
EDO-10, EDO-50, EDO-100 and EDO-200) are shown in Figure 4. All loading and unloading stages were performed by imposing discrete increments of vertical net stress, with each increment maintained for a period between 8 and 16 hours to ensure dissipation of excess pore water pressures. In test EDO-200, the two wetting/drying cycles were performed by changing suction in intervals of $50 \mathrm{kPa}$.

During all tests, water exchange from/to the sample was measured by means of two double-walled burettes and a differential pressure transducer. One burette was connected to the pore water drainage line while the second burette was isolated to provide a reference constant water level. The differential pressure transducer measured the water level change in the first burette with respect to the reference one and this was translated into a corresponding change of pore water volume.

\section{Blind test}

The stress path for the blind test is shown in Figure 5. After equalization at $q=0 \mathrm{kPa}$, $p=20 \mathrm{kPa}$ and $s=100 \mathrm{kPa}$, the sample was isotropically loaded at a constant suction of $100 \mathrm{kPa}$ and subsequently sheared at constant water content. It was not known apriori whether suction would increase or decrease during constant water content shearing, hence the initial loading stage was performed at a lower constant suction of $100 \mathrm{kPa}$ compared to the suction of $200 \mathrm{kPa}$ imposed during the triaxial tests used for calibration of model parameters. This ensured that the measured suction variation during constant water content shearing would fall between a suction of zero and 200 $\mathrm{kPa}$, which is the range covered by the calibration data. A constant water content shearing stage was deliberately chosen for the blind test so to assess the ability of the different models to predict strongly coupled hydro-mechanical soil behaviour. 
During shearing at constant water content, suction was measured by means of the axis translation technique. The pore water drainage line was isolated so that no pore water changes were allowed while the pressure transducer was kept in communication with the sample. Suction was then measured as the difference between the applied constant pore air pressure and the pore water pressure measured by the transducer.

\section{COMPARISON OF PREDICTED AND EXPERIMENTAL BEHAVIOUR}

All six teams returned predictions for tests TX02, TX07 and EDO-200 as well as for the blind test. The initial values of void ratio and degree of saturation (i.e. the values of void ratio and degree of saturation corresponding to the equalization stress state) were also predicted for each test. "Incremental" models predicting changes of void ratio, such as those by CU, EPFL, ENPC and UNSW, calculated the initial void ratio in each test by following a stress path originating from a single reference value of void ratio corresponding to the equalization stress state in the blind test, which was estimated on the basis of available data. On the other hand, "integrated" models that incorporate void ratio as a state variable, such as those by UNINA, UGLAS-1 and UGLAS-2, calculated the initial void ratio directly from the equalization stress state in each test.

Models were calibrated by the different teams using all thirteen tests provided and trying to give the best interpretation possible of the full set of experimental data. The chosen parameter values for all constitutive models are listed in Table 4. 
Two general observations can be made here about the calibration approaches followed by the different teams.

Firstly, ENPC and UNSW calibrated their respective water retention models considering the entire set of available data, including constant-suction oedometric and triaxial loading stages as well as the wetting-drying cycles of test EDO-200. On the other hand, CU, UGLAS-1, UGLAS-2 and UNINA used the constant-suction oedometric and triaxial loading stages but not the wetting-drying cycles of EDO-200, while EPFL only used the loading and wetting-drying stages of test EDO-200.

Secondly, because only one experimental isotropic compression at $s=200 \mathrm{kPa}$ was available from test TX03, all teams made use of additional data from constant-suction oedometric compression to calibrate the isotropic part of their mechanical models.

Teams ENPC, EPFL and UNSW, whose models adopt yield curves of the first class in the $s-p^{\prime}$ plane, started by defining the shape of the yield curve based on measured yield stresses with the spacing between constant-suction normal compression lines becoming then fixed as a consequence (see Appendix for the relationship between shape of the yield curve and spacing of constant-suction normal compression lines). In the ENPC model, the shape of the yield curve was defined to match the yield stresses from the five oedometric tests whereas, in the case of EPFL and UNSW, test EDO-200 was replaced by the isotropic loading of test TX03 at $s=200 \mathrm{kPa}$. This resulted in a steeper predicted yield curve between $s=50 \mathrm{kPa}$ and $s=200 \mathrm{kPa}$ for these two models. 
Teams CU, UGLAS-1, UGLAS-2 and UNINA, whose models adopt yield curves of the second class, started instead by defining the spacing between constant-suction normal compression lines on the basis of the five oedometric tests, which in turn fixed the shape of the yield curve in the $s-p^{\prime}$ plane. A detailed explanation of the calibration procedure followed by UGLAS can be found in the work by Gallipoli, D’Onza and Wheeler (Gallipoli et al., 2010).

In all seven models, the slopes of constant-suction normal compression lines were mainly determined from oedometric tests although ENPC, UGLAS-1, UGLAS-2 and UNINA took some account of data from the loading stages of the triaxial tests at $s=200 \mathrm{kPa}$.

In the following, predictions for tests TX02, TX07 and EDO-200, as well as for the blind test, are compared among themselves and with experiments.

\section{Triaxial test TXO2}

Figure 6 compares predicted and experimental data during the shearing stage of test TX02. Results from the loading stage are not presented given that the maximum mean net stress applied during this stage was only $20 \mathrm{kPa}$, with all models predicting small and mainly reversible changes of void ratio and degree of saturation over this limited stress range.

With reference to Figure 6, three types of results can be distinguished: i) mechanical uncoupled results depending only on the mechanical model but not on the water retention model, ii) hydraulic uncoupled results depending only on the water retention 
model but not on the mechanical model and iii) coupled results depending on both mechanical and water retention models.

CU, UGLAS-1, UGLAS-2, UNINA and UNSW all adopt stress tensors not depending on degree of saturation. Thus, for constant-suction tests, predictions in the $q-\varepsilon_{a}$ and $\varepsilon_{v^{-}}$ $\varepsilon_{a}$ planes by these five teams ( $\varepsilon_{a}$ and $\varepsilon_{v}$ are the axial and volumetric strains, respectively) represent mechanical uncoupled results. The corresponding predictions by ENPC and EPFL represent instead coupled results as, in this case, the constitutive stress path is influenced by the chosen water retention model through the dependency of the constitutive stress tensor on degree of saturation.

Predictions in the $S_{r^{-}} \mathcal{E}_{v}$ plane represent instead hydraulic uncoupled results for all teams. This is because all water retention models postulate a link between degree of saturation, suction and porosity, which can be recast as a link between degree of saturation, suction and volumetric strain, once the initial value of porosity at the start of shearing is taken into account. As a consequence, the shape of the predicted curve in the $S_{r}-\mathcal{E}_{v}$ plane depends on the water retention relationship alone, though the range of volumetric strains over which degree of saturation varies does depend also on the predicted mechanical response.

Finally, the predicted $S_{r}-\varepsilon_{a}$ relationships in Figure $6 \mathrm{~d}$ represent coupled results, as the shape of these curves comes from the combination of the previous $S_{r^{-}} \varepsilon_{v}$ and $\varepsilon_{v}-\varepsilon_{a}$ curves in Figures $6 \mathrm{~b}$ and $6 \mathrm{c}$ respectively. 
In Figure $6 \mathrm{a}$, the $q-\varepsilon_{a}$ relationships predicted by CU, UGLAS-1, UGLAS-2, UNINA and UNSW show an initial stiff response that is in good agreement with experiments as well as a relatively accurate prediction of critical strength. On the other hand, ENPC and EPFL predict lower values of initial stiffness and overestimate critical strength. Small changes of degree of saturation are calculated in Figure $6 \mathrm{c}$ for both these models, which suggests that their different predictions in the $q-\varepsilon_{a}$ plane are not attributable to the influence of the water retention relationship on the constitutive stress path (caused by the dependency of the constitutive stress tensor on degree of saturation). Instead the low shear stiffness predicted by the ENPC model is due to the narrow elastic range in the deviatoric plane and the particular kinematic hardening law inherited by the parent saturated model (see Table 1). The kinematic hardening law of the parent saturated model is also responsible for the significant overestimation of critical strength in the ENPC case. On the other hand, the low initial stiffness predicted by the EPFL model is mainly the consequence of the underestimation of the elastic stiffness at low stresses.

In Figure 6b all models except ENPC correctly predict dilatant behaviour, though the magnitude of dilation is underestimated in all cases. For the models predicting dilatant behaviour, the magnitude of the volumetric strain at the end of shearing depends on the relative positions of the constant-suction normal compression and critical state lines. It is therefore not surprising that the most accurate predictions are produced by the UNINA model, which offers complete flexibility in defining position and slope of constant-suction critical state lines in the $v-\ln p^{\prime}$ plane. On the other hand, in the EPFL and UNSW models, the position of constant-suction critical state lines can be varied to fit experimental data but their slope is constant and equal to the slope of 
normal compression lines. The least flexibility is offered by the CU, UGLAS-1 and UGLAS-2 models, for which the distance between constant-suction normal compression and critical state lines is fixed in their respective constitutive formulations. Hence, the underestimation of dilatant behaviour by the CU and UGLAS-1 models in Figure $6 \mathrm{~b}$ is a consequence of the excessive spacing between constant-suction critical state and normal compression lines in the $v-\ln p^{\prime}$ plane (similar to excessive spacing between saturated critical state and normal compression lines in the Modified Cam-clay model). Rather surprisingly, however, the volumetric strain predicted at the end of shearing by the UGLAS-2 model provides one of the best matches to the experimental data. This accurate prediction is caused by rotational hardening of the anisotropic yield locus, which results in a smaller distance between constant-suction normal compression and critical state lines for the UGLAS-2 model compared to the CU and UGLAS-1 models.

Figure 6c shows hydraulic uncoupled predictions running approximately parallel to the experiments in the $S_{r}-\varepsilon_{v}$ plane, which confirms that all water retention models capture reasonably well the variation of degree of saturation with volumetric strain (with the only exception of EPFL).

The vertical shift between curves in Figure $6 \mathrm{c}$ is caused by the different initial values of void ratio predicted at the start of the loading stage (i.e. after equalization), which has an impact on the corresponding calculation of degree of saturation. As previously mentioned, initial values of void ratio at equalization are computed by incremental models following a stress path originating from a reference soil state where void ratio had been previously estimated. There also appears to be a systematic error between 
predicted and experimental values of void ratio at the start of every test, i.e. all predictions appear to make an error of consistent sign, which is negative in Figure 6c but can also be positive as shown later in the paper. This is due to the large experimental scatter of the post-compaction values of void ratio among the tested samples (see Table 3). These differences are not entirely erased during equalization and produce a discrepancy of consistent sign between experimental and predicted values at the start of each test.

Unlike the uncoupled hydraulic predictions of Figure $6 c$, different models provide distinct mechanical uncoupled predictions (or nearly mechanical uncoupled predictions in the case of ENPC and EPFL) in Figure 6b, with markedly different forms of variation of volumetric strain with axial strain. The differences between predictions in Figure $6 \mathrm{~b}$ are also reflected in the variability of coupled predictions in Figure 6d.

\section{Triaxial test TX07}

Predicted and experimental results are compared for test TX07 in Figure 7 (loading stage) and Figure 8 (shearing stage). Figure $7 \mathrm{a}, 8 \mathrm{a}$ and $8 \mathrm{~b}$ show mechanical uncoupled predictions for CU, UGLAS-1, UGLAS-2, UNINA and UNSW, whereas they show coupled predictions for ENPC and EPFL (because of the different definition of constitutive stress in these two groups of models). Figures $7 \mathrm{~b}$ and $8 \mathrm{c}$ present hydraulic uncoupled predictions for all models. Finally, Figures $7 \mathrm{c}$ and $8 \mathrm{~d}$ show coupled predictions resulting from the combination of the previous two sets of results. 
As expected, ENPC, EPFL, UNINA, UGLAS-1, and UGLAS-2 predict a sharp change of stiffness at yielding in Figure 7a while CU and UNSW show a gradual transition from elastic to plastic behaviour that better reproduces the experimental trend. Consistent predictions of yield stresses are obtained by the different models, which are also in reasonably good agreement with experiments. The smaller preconsolidation stress predicted by ENPC is again the consequence of the narrow elastic range assumed in the deviatoric plane by this model.

The prediction by ENPC also shows a stiffer post-yield response compared to other curves, a behaviour that is similarly observed during constant-suction loading in the blind test and test EDO-200 as it will be later shown. It is interesting to note that the ENPC model predicts the stiffest post-yield response in the $e-\ln p$ plane (where $e$ is the void ratio) despite assuming the smallest plastic stiffness in the $e-\ln p^{\prime}$ plane, as indicated by the relatively small value of parameter $K_{0}^{p}$ in Table 4 . This apparently surprising result is the consequence of the incorporation of the additive term $\chi_{2}$ in the constitutive stress definition of equation (3), which results in a comparatively stiffer response when void ratio is plotted against mean constitutive stress rather than mean net stress. It also suggests that the particular choice of constitutive stress tensor has an influence on calibration of plastic stiffness.

Hydraulic uncoupled predictions in Figures $7 \mathrm{~b}$ and $8 \mathrm{c}$ confirm that all water retention models capture relatively well the dependency of degree of saturation on volumetric strain, with the only exception of EPFL which significantly overestimates the increase of degree of saturation during the compression stage. This is due to the particular water retention calibration performed by this team and, more specifically, to the 
choice of an excessively large value of parameter $\pi_{h}$ (see Table 4), which relates degree of saturation to volumetric strain and had been selected on the basis of test EDO-200 alone.

With regard to the shape of predicted curves, the relationship between degree of saturation and void ratio in Figure $7 \mathrm{~b}$, or between degree of saturation and volumetric strain in Figure 8c, shows smaller differences between models than the relationship between volumetric strain and axial strain in Figure 8b (with the exception of EPFL). This confirms the greater uniformity of hydraulic uncoupled predictions compared to mechanical uncoupled predictions and, hence, indicates that greater consistency exists between water retention models compared to mechanical models at least for paths that do not involve suction or stress reversals. Similarly to test TX02, Figure 8b shows that the prediction of the final volumetric strain is least accurate for CU and UGLAS-1, which is again due to the overestimation of the distance between constant-suction normal compression and critical state lines as previously explained. On the other hand, the most accurate prediction is this time provided by ENPC followed by UNINA.

Coupled predictions mirror features of mechanical uncoupled predictions because of their dependency on both mechanical and water retention models. For example, the sharp mechanical yielding predicted by classic elasto-plastic models is also evident in the coupled predictions of Figure $7 \mathrm{c}$ but not in the hydraulic uncoupled predictions of Figure $7 \mathrm{~b}$. Due to the greater accuracy of hydraulic uncoupled predictions compared to mechanical uncoupled predictions, potential errors in the predicted shape of coupled relationships is mainly the consequence of inadequacies of the mechanical 
model rather than the water retention model (with the exception of EPFL where the calibration of the water retention model is responsible for the large deviation from experimental results).

\section{Blind triaxial test}

Predicted and experimental results are compared for the blind test in Figure 9 (loading stage at $s=100 \mathrm{kPa}$ ) and Figure 10 (shearing stage at constant water content).

As previously discussed, Figure 9a shows relatively large errors of consistent sign for the predicted initial values of void ratio though, unlike test TX07, experimental values are now underestimated by all teams.

Compared to test TX07, greater inconsistencies exist between predicted yield stresses in Figure 9a. In particular, ENPC, UGLAS-1, UGLAS-2 and UNINA underestimate yield stress while EPFL and UNSW overestimate it.

Calibration of the former group of four models took into account all five constantsuction oedometric compressions when defining the shape of the yield curve in the $s$ $p^{\prime}$ plane. This was done either directly, by fitting yield stresses at different suctions, as in the case of ENPC, or indirectly, by fixing the spacing and slopes of constantsuction normal compression lines in the $v-\ln p^{\prime}$ plane, as in the case of UGLAS-1, UGLAS-2 and UNINA. In all four cases, once the shape of the yield curve had been defined, its position was adjusted to optimize prediction of yield stresses during both triaxial and oedometric tests. Figure 9a shows that the above procedure predicts a 
decrease of yield stress with decreasing suction that slightly underestimates the measured value at $s=100 \mathrm{kPa}$.

In the UNSW and EPFL models, the shape of the yield curve in the $s-p$ ' plane was instead defined after replacing the yield stress of test EDO-200 with that of the isotropic loading of test TX03 (also at $s=200 \mathrm{kPa}$ ), which resulted in a steep variation of yield stress with suction. For $s \geq 50 \mathrm{kPa}$, the yield stress remained approximately constant and equal to the value measured at $s=200 \mathrm{kPa}$ in test TX03 so that the experimental yield stress at $s=100 \mathrm{kPa}$ is overestimated (see Figure 9a).

Similarly to test TX07, remarkably consistent shapes are obtained for the hydraulic uncoupled predictions in the $S_{r^{-}} e$ plane for six of the seven models (Figure 9b), with the different simulation from EPFL caused by an inappropriate choice of value for parameter $\pi_{h}$ as previously explained. Coupled predictions in Figure 9c are obtained by combining the two sets of curves in Figures $9 \mathrm{a}$ and $9 \mathrm{~b}$ respectively. Coupled predictions therefore show features from both the above sets of results, such as the occurrence of a sharp yielding point similar to Figure 9a, and the large increase of degree of saturation predicted by EPFL similar to Figure 9b. The initial value of degree of saturation is consistently overestimated by all models in Figures $9 \mathrm{~b}$ and $9 \mathrm{c}$, which corresponds to the systematic underestimation of initial void ratio in Figure 9a.

During the subsequent shearing stage at constant water content, six out of seven models calculate similar values of critical strength within a range of about $50 \mathrm{kPa}$ (Figure 10a). All predictions fall however short of the experimental critical strength by a margin greater than $100 \mathrm{kPa}$ due to the unexpectedly high critical strength 
measured during constant water shearing. This is considerably higher than the strength recorded in tests TX01, TX02, TX06 and TX07 at a suction of $200 \mathrm{kPa}$, despite a value of suction lower than $200 \mathrm{kPa}$ is measured at critical state during constant water shearing.

Prediction of volumetric strains in Figure 10b show that, unlike tests TX02 and TX07, the CU and UGLAS-1 models provide the closest match to the experimental data, followed by UNINA and UGLAS-2. The accurate prediction of volumetric strain at critical state by the CU and UGLAS-1 models is rather unexpected and inconsistent with the previous simulations of tests TX02 and TX07. This rather surprising result is possibly the consequence of the disagreement between measured and predicted values of suction during constant water content shearing, as it will be shown later.

Considering all shearing stages in test TX02, test TX07 and the blind test, UNINA provides the most accurate prediction of volumetric strains overall, which is an expected result given the flexibility of this model in fitting the experimental volumetric behaviour at critical state. Rather unexpected is perhaps the good accuracy of UGLAS-2, which confirms that the adoption of an anisotropic yield locus (i.e. a yield locus inclined at angle with respect to the hydrostatic axis in the principal stress space) improves prediction of volumetric strains at critical state.

Similarly to tests TX02 and TX07, the shape of the predicted curves in the $S_{r^{-}} \mathcal{E}_{v}$ plane (Figure 10c) is closer to the experimental data compared to predicted curves in the $\varepsilon_{v^{-}}$ $\varepsilon_{a}$ plane (Figure 10b). Note however that, unlike the constant suction tests TX02 and TX07, in this case the predicted curves in the $S_{r^{-}}-\mathcal{E}_{v}$ plane do not depend on the water 
retention model but only on the initial values of degree of saturation, $S_{r 0}$ and void ratio, $e_{0}$ at the start of shearing. The curves in Figure 10c can be in fact calculated by imposing the condition of zero water content change during shearing while taking into account the relation between void ratio and volumetric strain, i.e. $e=e_{0}-\varepsilon_{v}\left(1+e_{0}\right)$ :

$$
S_{r} e=S_{r 0} e_{0} \Rightarrow S_{r}=\frac{S_{r 0} e_{0}}{e_{0}-\varepsilon_{v}\left(1+e_{0}\right)} \Rightarrow S_{r}=\frac{S_{r 0} n_{0}}{n_{0}-\varepsilon_{v}}
$$

where $n_{0}$ is the value of porosity at the start of shearing. Consistent with equation (9), teams predicting large volumetric strains in Figure 10b, such as CU and UGLAS-1, also predict large increases of degree of saturation in Figure 10c.

Because the shape of predictions in the $S_{r^{-}} \varepsilon_{v}$ plane (Figure 10c) does not depend on the water retention model, the shape of predictions in the $S_{r}-\varepsilon_{a}$ plane (Figure 10d) is also independent of the water retention model and is governed by the mechanical model alone. Therefore, unlike tests TX02 and TX07, the variability of shapes of predicted curves in the $S_{r^{-}}-\varepsilon_{a}$ plane is largely attributable to the variability of shapes of predicted curves in the $\varepsilon_{v}-\varepsilon_{a}$ plane (Figure 10b) (the slight difference between the shapes of predicted curves in the $S_{r^{-}} \varepsilon_{v}$ plane, which is caused by the different initial values of degree of saturation and void ratio, has a much smaller effect on the variability of shapes of predicted curves in the $S_{r}-\varepsilon_{a}$ plane). In fact, if the $S_{r}-\varepsilon_{a}$ predictions are shifted along the vertical axis to start from the same point, a similar distribution of curves as for the $\varepsilon_{v}-\varepsilon_{a}$ predictions is obtained (the two distributions would look even more similar if the shape of the predicted $S_{r^{-}}-\mathcal{E}_{v}$ relationships in Figure 10c were exactly the same for all models which, according to equation (9), would only happen if the initial values of degree of saturation, $S_{r 0}$ and void ratio, $e_{0}$ coincided in all predictions). 
During constant water shearing, the occurrence of volumetric strain and the consequent variation of degree of saturation induce a change of suction according to the chosen water retention model. The variation of suction calculated by the different models during shearing is presented in Figure 10e, together with the corresponding experimental data.

Figure 10e shows significant discrepancies between predictions and even opposite trends. This contradictory range of responses during constant water shearing is explained by the incidence of two contrasting factors, trying to control the variation of suction in opposite directions. For all water retention models, an increase of degree of saturation at constant volumetric strain induces a drop in suction as $\frac{\partial s}{\partial S_{r}}<0$ while, on the other hand, a compressive volumetric strain at constant degree of saturation produces an increase of suction as $\frac{\partial s}{\partial \varepsilon_{v}}>0$. Whether a drop or an increase of suction is predicted therefore depends on which of the above two factors is dominant.

Given that all predicted $S_{r}-\mathcal{E}_{v}$ curves in Figure 10c are approximately parallel, the corresponding increments of degree of saturation and volumetric strain are approximately the same for all models at any point during shearing. The prediction of opposite suction gradients in Figure 10e can not therefore be attributed to differences in the ratio between increments of degree of saturation and volumetric strain predicted by the distinct models. On the other hand, it depends on whether the chosen water retention model implies greater sensitivity of suction to changes of degree of 
saturation rather than volumetric strain or vice versa, i.e. it depends on the relative magnitude of the two partial derivatives $\frac{\partial s}{\partial S_{r}}$ and $\frac{\partial s}{\partial \varepsilon_{v}}$.

In summary, at any point during shearing, the direction of suction variation depends on the water retention model alone while the magnitude of such variation depends also on the mechanical model, which controls the magnitude of volumetric strain and, hence, change of degree of saturation during constant water content shearing. This is consistent with the fact that the absolute values of the final suction changes in Figure 10e are largest for CU and UGLAS-1, which are also the two models predicting the largest increases of volumetric strain and degree of saturation over the entire shearing stage (see Figure 10c).

UGLAS-1, UGLAS-2 and UNINA all use the same water retention model (see Table 1), although UGLAS-1 and UGLAS-2 adopt different parameter values compared to UNINA (see Table 4), but the predicted suction variation follows opposite directions, with UGLAS-1 and UGLAS-2 predicting an increase of suction while UNINA showing a slight drop. This demonstrates that the sign of the suction gradient in Figure 10e does not necessarily depend on the chosen type of water retention model but can also be a consequence of the particular calibration of one given model. This example also shows that constant water content tests can prove useful in refining calibration of water retention models due to the high sensitivity of the predicted response to the relevant parameter values. 
It is also important to highlight here that any error in the prediction of suction during constant water, or partly drained, shearing will impact on the prediction of other important variables such as for example the strength at critical state.

\section{Oedometric test EDO-200}

Predicted and experimental results are compared for the oedometric test EDO-200 in Figure 11 (first wetting/drying cycle stage at $\sigma_{v}=20 \quad \mathrm{kPa}$ ), Figure 12 (loading/unloading/reloading stage at $s=200 \mathrm{kPa}$ ) and Figure 13 (second wetting/drying cycle stage at $\sigma_{v}=800 \mathrm{kPa}$ ).

Figure 11 compares predicted and experimental data during the first wetting/drying cycle for the two hysteretic models of EPFL and UNSW (Figure 11a) and for the five non-hysteretic models of CU, ENPC, UGLAS-1, UGLAS-2 and UNINA (Figure 11b). Predicted variations of void ratio are not presented here due to their limited interest (they are very small and largely reversible).

Inspection of Figures $11 \mathrm{a}$ and $11 \mathrm{~b}$ confirms that incorporation of hydraulic hysteresis improves considerably the prediction of degree of saturation during the wetting drying/cycle with both EPFL and UNSW accurately capturing the irreversible change of degree of saturation at the end of the cycle. As expected, CU, ENPC, UGLAS-1, UGLAS-2 and UNINA generally predict reversible changes of degree of saturation. Only the ENPC model shows a slight irreversibility in the predicted variation of degree of saturation around the inversion point because of the occurrence of a small amount of plastic volumetric strains. Predictions by CU and ENPC match relatively well the wetting branch of the cycle while predictions by UGLAS-1, UGLAS-2 and 
UNINA lie close to the experiments at the start of wetting but then tend to fall below the measured data as suction is reduced.

Predicted and experimental results during the loading/unloading/reloading cycle are compared in Figures 12a and 12b. Figure 12a shows larger differences between predicted yield stresses compared to the anisotropic loading stage at the same level of suction in test TX07 (see Figure 7a). This is caused by the variability of the stress paths computed by the different models under radially constrained conditions, which leads to yielding over different regions of the stress space. Plastic deformation after yielding is overestimated by all models (with the only exception of ENPC) due to underestimation of the yield stress rather than underestimation of plastic stiffness. In the case of ENPC, the prediction of a stiffer post-yield response (as already observed during the loading stages of test TX07 and the blind test) compensates for the underestimation of the yield stress resulting in a better match to the experimental data compared to other models.

In Figure $12 \mathrm{~b}$, the degree of saturation predicted at the start of loading by the five non-hysteretic models (i.e. CU, ENPC, UGLAS-1, UGLAS-2 and UNINA) is considerably smaller than the experimental value because of the significant underestimation at the end of the previous drying stage. On the other hand, the overestimation of volumetric compression during loading in Figure 12a tends to produce a corresponding overestimation of the increase of degree of saturation in Figure 12b. 
Figure 13 compares predicted and experimental data during the second wetting/drying cycle both in terms of deformation (Figure 13a) and water retention (Figures 13b and 13c). At the start of wetting, the predicted values of void ratio and degree of saturation are in all cases lower than the experiments due to accumulated errors during the previous test stages.

During wetting, the amount of collapse depends on the spacing between constantsuction normal compression lines. The CU, ENPC, UGLAS-1, UGLAS-2 and UNINA models predict a noticeable amount of collapse in Figure 13a. In these models, the spacing between constant-suction normal compression lines had been calibrated by taking into account data from all five constant-suction oedometric compression curves. However, one difference between the CU, UGLAS-1, UGLAS-2 and UNINA models (which largely overestimate collapse during wetting) and the ENPC model (which predicts instead a smaller and more accurate value of collapse) is that, in the former case, spacing had been directly fixed to match the distance between constant-suction oedometric compression curves whereas, in the latter case, it had been indirectly fixed by defining the shape of the yield curve in the $s-p^{\prime}$ plane.

As for the other two models, EPFL predicts a negligible amount of collapse while, in the case of UNSW, collapse is concentrated during the later stages of wetting when suction changes from about $80 \mathrm{kPa}$ to $55 \mathrm{kPa}$. This is due to the fact that, as mentioned previously, both these models assume a yield curve in the $s-p^{\prime}$ plane that becomes very steep when suction becomes greater than $50 \mathrm{kPa}$ in the case of EPFL and $80 \mathrm{kPa}$ in the case of UNSW. This implies the existence of very small distances 
between constant-suction normal compression lines in the $v-\ln p^{\prime}$ plane for suctions greater than the above values.

The variation of degree of saturation is presented in Figure $13 \mathrm{~b}$ for the two hysteretic models and in Figure 13c for the five non-hysteretic models. In this case, unlike the first wetting/drying cycle, all seven models predict some irreversible increase in degree of saturation at the end of the cycle, albeit for different reasons. The relatively accurate prediction of the change of degree of saturation by some of the nonhysteretic models is the consequence of the overestimation of volumetric collapse during wetting. On the other hand, the irreversible changes of degree of saturation predicted by the two hysteretic models are predominantly caused by water retention hysteresis, given the small or negligible changes of void ratio predicted by these models during the wetting/drying cycle.

\section{CONCLUSIONS}

The paper presents the results from a collaborative piece of research undertaken by seven universities to benchmark different approaches to modelling mechanical and water retention behaviour of unsaturated soils. Seven different constitutive models have been independently calibrated by different teams of researchers based on the same set of thirteen suction controlled triaxial and oedometer tests performed on compacted silty soil samples. The calibrated constitutive models have then been used to predict soil behaviour during three of the thirteen calibration tests, as well as during one "blind" test whose results had not been previously published. 
The main features of the seven models are first compared with particular reference to water retention behaviour, stress tensor definition, effect of suction on the mechanical response and nature of irreversible deformation. Through this comparison, a model classification matrix has been proposed based on the adopted type of constitutive stress and yield curve in the $s-p^{\prime}$ plane (see Table 2). The intrinsic link between the definition of the yield curve in the $s-p^{\prime}$ plane and constant-suction normal compression lines in the $v-\ln p^{\prime}$ plane has also been highlighted. The proposed classification is not necessarily restricted to the models considered in this work and could be generally extended to other formulations in the literature.

Predictions from different models are interpreted in the context of the respective analytical formulations and calibration choices made by participating teams. Models with similar features appear to produce qualitatively coherent predictions although quantitative discrepancies are often observed. In several cases, these discrepancies are the consequence of the chosen calibration approach rather than the specific features of the model. For example, UGLAS-1, UGLAS-2 and UNINA all used the same water retention model; nevertheless the suction variation predicted by UGLAS-1 and UGLAS-2 during constant water content shearing in the blind test follows an opposite direction compared to UNINA. This is due to the selection of different parameter values by UGLAS-1 and UGLAS-2 compared to UNINA, which emphasizes the difficulties associated with model calibration and, especially, the importance of identifying the most sensitive aspects of soil behaviour for the selection of particular model parameters. In general, these results highlight the danger of formulating ever more sophisticated constitutive models without dedicating the necessary attention to the development of robust procedures for selecting parameter values. 
Based on the analysis of all results, it is concluded that hydraulic uncoupled predictions (i.e. predictions governed only by the water retention model) show smaller differences among teams and are generally closer to the experimental data than mechanical uncoupled predictions (i.e. predictions governed only or predominantly by the mechanical model). This also confirms that a greater degree of uniformity exists across water retention models in comparison to mechanical models.

The variation of volumetric strain during shearing appears particularly difficult to predict and this is intrinsically related to the ability of each model of matching the distance between constant-suction normal compression and critical state lines in the $v$ - $\ln p^{\prime}$ plane. Potential inaccuracies in the prediction of volumetric strain during shearing have also consequences on the corresponding prediction of degree of saturation because of the assumed dependency of degree of saturation on soil porosity. Errors in the calculated relationship between degree of saturation and axial strain during shearing are therefore more likely to be the consequence of an inaccurate prediction of volumetric strain by the mechanical model rather than a deficiency of the water retention model itself.

During shearing at constant water content, the relationships between suction and axial strain predicted by the different teams show significant discrepancies and even opposite trends. This is caused by the strong sensitivity of this type of prediction to the chosen water retention model and its calibration. The direction of suction variation depends on the chosen water retention model alone and, more specifically, on the relative sensitivity of suction variation to changes in degree of saturation and 
volumetric strain. The magnitude of suction variation depends instead on the size of the changes of degree of saturation and volumetric strain, which is governed by both mechanical and water retention models.

Any error in the prediction of suction during constant water content (or partly drained) shearing will impact on the prediction of strength at critical state. Therefore the choice of an accurate and well-calibrated water retention model becomes particularly important during analyses that involve strong hydro-mechanical coupling.

\section{ACKNOWLEDGEMENTS}

The financial support of the European Commission through funding of the "Marie Curie" Research Training Network MUSE (Mechanics of Unsaturated Soils for Engineering - Contract: MRTN-CT-2004-506861) is acknowledged. Contributions of

Dr Claudia Zingariello of the UNINA team and Drs Michael Habte and Adrian Russell of the UNSW team are also gratefully acknowledged.

\section{REFERENCES}

Alonso, E. E., Gens, A. \& Josa, A. (1990). A constitutive model for partially saturated soils. Géotechnique 40, No. 3, 405-430.

Brooks, R. N. \& Corey, A. T. (1964). Hydraulic properties of porous media. Colorado State University Hydrology Paper 3, 27.

Cambou, B. \& Jafari, K. (1988). Modèle de comportement des sols non cohérents. Revue Française de Géotechnique 44, 43-55. 
Casini F.. Effetti del grado di saturazione sul comportamento meccanico del limo, PhD Thesis. Universitá degli Studi di Roma “La Sapienza”, Rome, 2008.

Coussy O. and Dangla P.. Approche énergétique du comportement des sols non saturés. Mécanique des sols non saturés (Coussy, O. \& Fleureau, J-M (eds)). Lavoisier, Paris,2002.

Cui, Y.J. \& Delage, P. (1996), Yielding and plastic behaviour of an unsaturated compacted silt. Géotechnique 46, 291-311.

Dangla, P.. Plasticité et hysteresis. Mécanique des sols non saturés (Coussy, O. \& Fleureau, J-M (eds)). Lavoisier, Paris, 2002.

D'Onza F. Gallipoli D. and Wheeler S. Effect of anisotropy on the prediction of unsaturated soil response under triaxial and oedometric conditions. Proc. $5^{\text {th }}$ Int. Conf. on Unsaturated Soils (Alonso E.E. and Gens A. (eds)). Balkema, Rotterdam, 2010, pp. 787-794.

Gallipoli, D., Wheeler, S. \& Karstunen, M. (2003). Modelling the variation of degree of saturation in a deformable unsaturated soil. Géotechnique 53, No. 1, 105-112.

Gallipoli, D., D’Onza, F. \& Wheeler, S. (2010). A sequential method for selecting parameter values in the Barcelona basic model. Canadian Geotechnical Journal 47, No. $11,1175-1186$. 
Gens A. Constitutive modelling: application to compacted soils. Proc. $1^{\text {st }}$ Int. Conf. on Unsaturated Soils (Alonso E.E. and Delage P. (eds)). Balkema, Rotterdam, 1996, pp. $1179-1200$.

Gudehus, G. \& Mašín, D. (2009). Graphical representation of constitutive equations. Géotechnique 52, No. 2, 147-151.

Hujeux J. Une loi de comportement pour le chargement cyclique des sols. Génie Parasismique. Les éditions de l'ENPC, Paris, 1985, pp. 287-353.

Khalili, N., Habte, M.A. \& Valliappan, S. (2005). A bounding surface plasticity model for cyclic loading of granular soils. International Journal for Numerical Methods in Eng. 63, No. 14, 1939-1960.

Khalili, N., Habte, M.A. \& Zargarbashi, S. (2008). A fully coupled flow deformation model for cyclic analysis of unsaturated soils including hydraulic and mechanical hysteresis. Computers and Geotechnics 35, No.6, 872-889.

Khalili, N. \& Khabbaz, M.H. (1998). A unique relationship for $\chi$ for the determination of the shear strength of unsaturated soils. Géotechnique 48, No. 2, 1-7.

Mašín, D. (2005). A hypoplastic constitutive model for clays. International Journal for Numerical and Analytical Methods in Geomechanics 29, No. 4, 311-336. 
Mašín, D. (2010). Predicting the dependency of a degree of saturation on void ratio and suction using effective stress principle for unsaturated soils. International Journal for Numerical and Analytical Methods in Geomechanics 34, No. 1, 73-90.

Mašín, D. \& Herle, I. (2005). State boundary surface of a hypoplastic model for clays. Computers and Geotechnics 32, No. 6, 400-410.

Mašín, D. \& Khalili, N. (2008). A hypoplastic model for mechanical response of unsaturated soils. International Journal for Numerical and Analytical Methods in Geomechanics 32, No. 15, 1903-1926.

Nuth M. and Laloui L. New insight into the unified hydro-mechanical constitutive modelling of unsaturated soils. Proc. $3^{\text {rd }}$ Asian Conference on Unsaturated Soils (Yin Z.Z., Yuan Y.P. and Chiu A.C.F. (eds.)). Science Press, Beijing, 2007, pp. 109-126.

Nuth, M. \& Laloui, L. (2008). Advances in modelling hysteretic water retention curve in deformable soils. Computers and Geotechnics 35, No. 6 , 835-844.

Pereira, J. M., Wong, H., Dubujet, P. \& Dangla, P. (2005). Adaptation of existing behaviour models to unsaturated states: application to CJS model. International Journal for Numerical and Analytical Methods in Geomechanics 29, No. 11, 11271155. 
Roscoe K.H. and Burland J.B. On the generalised stress-strain behaviour of wet clay. Engineering Plasticity (Heyman J. and Leckie F.A. (eds)). Cambridge University Press, Cambridge, 1968, pp. 535-609.

Van Genuchten, M. T. (1980). A closed-form equation for predicting the hydraulic conductivity of unsaturated soil. Soil Science Society American Journal 44, No. 5, 892-898.

Wheeler, S. \& Sivakumar, V. (1995). An elasto-plastic critical state framework for unsaturated soil. Géotechnique 45, No. 1, 35-53.

Wheeler, S., Näätänen, A., Karstunen, M. \& Lojander, M. (2003). An anisotropic elastoplastic model for soft clays. Canadian Geotechnical Journal 40, No.2, 403-418. 


\section{APPENDIX}

A linear relationship in the $v-\ln p^{\prime}$ plane is assumed for the saturated normal compression line corresponding to $s=s_{e}$ :

$v=N-\lambda \ln p_{0}^{\prime}\left(s_{e}\right)$

where $\lambda$ is the slope and $N$ is the intercept at $p^{\prime}{ }_{0}\left(s_{e}\right)=1$.

By following an elastic path inside the yield locus in the $s-p^{\prime}$ plane, the specific volume at a yield stress $p_{0}^{\prime}(s)$ is obtained as:

$v=N-\lambda \ln p_{0}^{\prime}\left(s_{e}\right)+\left.\Delta v^{e}\right|_{s_{e}} ^{s}-\kappa \ln \frac{p_{0}^{\prime}(s)}{p_{0}^{\prime}\left(s_{e}\right)}$

where $\left.\Delta v^{e}\right|_{0} ^{s}$ is the elastic change of specific volume when suction varies from $s_{e}$ to $s$ while $\kappa$ is the slope of the elastic compression line in the $v-\ln p^{\prime}$ plane.

By substituting for $p_{0}^{\prime}\left(s_{e}\right)$ from equation (7) into equation (A2) and rearranging, one obtains the following expression for the constant-suction normal compression line at suction $s$ :

$v=N+\frac{\lambda-\kappa}{\omega_{2}} \ln \omega_{1}+\left.\Delta v^{e}\right|_{s_{e}} ^{s}-\frac{\lambda-\kappa}{\omega_{2}} \ln \left(p_{0}^{\prime}(s)-\omega_{3}\right)-\kappa \ln p_{0}^{\prime}(s)$

which can be rewritten in the following simpler form: 
$v=N(s)-\lambda(s) \ln p_{0}^{\prime}(s)$

The slope $\lambda(s)$ and spacing $N(s)$ of constant-suction normal compression lines are therefore given by:

$$
\begin{aligned}
& \lambda(s)=\frac{\lambda-\kappa}{\omega_{2}} \frac{\ln \left(p_{0}^{\prime}(s)-\omega_{3}\right)}{\ln p_{0}^{\prime}(s)}+\kappa \\
& N(s)=N+\frac{\lambda-\kappa}{\omega_{2}} \ln \omega_{1}+\left.\Delta v^{e}\right|_{s_{e}} ^{s}
\end{aligned}
$$

For each of the three classes of yield curve, the slope $\lambda(s)$ and spacing $N(s)$ of constant-suction normal compression lines are therefore given as follows.

\section{$\underline{\text { Class a) }}$}

$$
\left.\begin{array}{l}
\omega_{2}=1 \\
\omega_{3}=0
\end{array}\right\} \Rightarrow \begin{gathered}
\lambda(s)=\lambda \\
N(s)=N+(\lambda-\kappa) \ln \omega_{1}+\left.\Delta v^{e}\right|_{s_{e}} ^{s}
\end{gathered}
$$

Constant-suction normal compression lines have constant slope while spacing depends on function $\omega_{1}$.

\section{$\underline{\text { Class b) }}$}

$$
\omega_{3}=0 \Rightarrow \begin{gathered}
\lambda(s)=\frac{\lambda-\kappa}{\omega_{2}}+\kappa \\
N(s)=N+\frac{\lambda-\kappa}{\omega_{2}} \ln \omega_{1}+\left.\Delta v^{e}\right|_{s_{e}} ^{s}
\end{gathered}
$$

Constant-suction normal compression lines have variable slope depending on function $\omega_{2}$ and spacing depending on function $\omega_{1}$.

\section{$\underline{\text { Class c) }}$}




$$
\omega_{2}=1 \Rightarrow \begin{aligned}
& \lambda(s)=(\lambda-\kappa) \frac{\ln \left(p_{0}^{\prime}(s)-\omega_{3}\right)}{\ln p_{0}^{\prime}(s)}+\kappa \\
& N(s)=N+(\lambda-\kappa) \ln \omega_{1}+\left.\Delta v^{e}\right|_{s_{e}} ^{s}
\end{aligned}
$$

Constant-suction normal compression lines are not straight lines in the $v-\ln p^{\prime}$ plane (i.e. the secant slope depends on stress state) and spacing depends on function $\omega_{1}$. 


\section{TABLES}

Page 48 of 78 


\begin{tabular}{|c|c|c|c|c|}
\hline Team & $\begin{array}{l}\text { Water retention } \\
\text { model }\end{array}$ & Mechanical model & Difference with published versions & $\begin{array}{l}\text { Reference saturated } \\
\text { mechanical model }\end{array}$ \\
\hline $\mathrm{CU}$ & $\begin{array}{l}\text { Mašín, D. (2010). } \\
\text { Predicting the } \\
\text { dependency of a } \\
\text { degree of saturation } \\
\text { on void ratio and } \\
\text { suction using } \\
\text { effective stress } \\
\text { principle for } \\
\text { unsaturated soils. } \\
\text { International } \\
\text { Journal for } \\
\text { Numerical and } \\
\text { Analytical Methods } \\
\text { in Geomechanics } \mathbf{3 4}, \\
\text { No. 1, 73-90. }\end{array}$ & $\begin{array}{l}\text { Mašín, D. \& Khalili, } \\
\text { N. (2008). A } \\
\text { hypoplastic model } \\
\text { for mechanical } \\
\text { response of } \\
\text { unsaturated soils. } \\
\text { International } \\
\text { Journal for } \\
\text { Numerical and } \\
\text { Analytical Methods } \\
\text { in Geomechanics } \mathbf{3 2} \text {, } \\
\text { No. 15, 1903-1926. }\end{array}$ & $\begin{array}{l}\text { The definition of the constitutive } \\
\text { stress variable takes into account the } \\
\text { dependency of air entry value on } \\
\text { void ratio, as predicted by the } \\
\text { adopted water retention model } \\
\text { proposed by Mašín (Mašín, 2010). }\end{array}$ & $\begin{array}{l}\text { Mašín, D. (2005). A } \\
\text { hypoplastic } \\
\text { constitutive model } \\
\text { for clays. } \\
\text { International } \\
\text { Journal for } \\
\text { Numerical and } \\
\text { Analytical Methods } \\
\text { in Geomechanics 29, } \\
\text { No. 4, 311-336. }\end{array}$ \\
\hline EPFL & $\begin{array}{l}\text { Nuth, M. \& Laloui } \\
\text { L. (2008). Advances } \\
\text { in modelling } \\
\text { hysteretic water } \\
\text { retention curve in } \\
\text { deformable soils. } \\
\text { Computers and } \\
\text { Geotechnics } \mathbf{3 5} \text {, No. } \\
6,835-844 \text {. }\end{array}$ & $\begin{array}{l}\text { Nuth M. and Laloui } \\
\text { L. New insight into } \\
\text { the unified hydro- } \\
\text { mechanical } \\
\text { constitutive } \\
\text { modelling of } \\
\text { unsaturated soils. } \\
\text { Proc. } 3^{\text {rd }} \text { Asian } \\
\text { Conference on } \\
\text { Unsaturated Soils } \\
\text { (Yin Z.Z., Yuan Y.P. } \\
\text { and Chiu A.C.F. } \\
\text { (eds.)). Science } \\
\text { Press, Beijing, 2007, } \\
\text { pp. 109-126.. }\end{array}$ & $\begin{array}{l}\text { The published mechanical model } \\
\text { uses the Van Genuchten (1980) } \\
\text { equation to calculate degree of } \\
\text { saturation as a function of suction. } \\
\text { However, an improved water } \\
\text { retention model has been here used, } \\
\text { which incorporates the effects of } \\
\text { both hydraulic hysteresis and soil } \\
\text { density as described by Nuth and } \\
\text { Laloui (Nuth and Laloui, 2008) }\end{array}$ & $\begin{array}{l}\text { Hujeux J. Une loi de } \\
\text { comportement pour } \\
\text { le chargement } \\
\text { cyclique des sols. } \\
\text { Génie Parasismique. } \\
\text { Les éditions de } \\
\text { l'ENPC, Paris, 1985, } \\
\text { pp. 287-353. }\end{array}$ \\
\hline ENPC & $\begin{array}{l}\text { Brooks, R. N. \& } \\
\text { Corey, A. T. (1964). } \\
\text { Hydraulic properties } \\
\text { of porous media. } \\
\text { Colorado State } \\
\text { University } \\
\text { Hydrology Paper } 3 \text {, } \\
27 .\end{array}$ & $\begin{array}{l}\text { Pereira, J. M., Wong, } \\
\text { H., Dubujet, P. \& } \\
\text { Dangla, P. (2005). } \\
\text { Adaptation of } \\
\text { existing behaviour } \\
\text { models to } \\
\text { unsaturated states: } \\
\text { application to CJS } \\
\text { model. International } \\
\text { Journal for } \\
\text { Numerical and } \\
\text { Analytical Methods } \\
\text { in Geomechanics } \mathbf{2 9} \text {, } \\
\text { No. 11, 1127-1155. }\end{array}$ & $\begin{array}{l}\text { The influence of soil density on } \\
\text { water retention behaviour is } \\
\text { modelled by extending the Brooks } \\
\text { and Corey water retention curve } \\
\text { (Brooks and Corey, 1964) to } \\
\text { incorporate the following } \\
\text { dependency of slope } \lambda \text { and air entry } \\
\text { suction } s_{e} \text { on porosity, } \phi \text { : } \\
\lambda(\phi)=\lambda_{0} \exp \left(-A \cdot\left(\phi-\phi_{\text {ref }}\right)\right) \\
s_{\mathrm{e}}(\phi)=s_{\mathrm{e} 0} \exp \left(-A \cdot\left(\phi-\phi_{\mathrm{ref}}\right)\right) \\
\text { where } \lambda_{0}, s_{e 0}, A \text { and } \phi_{r e f} \text { are model } \\
\text { parameters. }\end{array}$ & $\begin{array}{l}\text { Cambou, B. \& Jafari, } \\
\text { K. (1988). Modèle } \\
\text { de comportement des } \\
\text { sols non cohérents. } \\
\text { Revue Française de } \\
\text { Géotechnique 44, } \\
\text { 43-55. }\end{array}$ \\
\hline $\begin{array}{c}\text { UGLAS } \\
1\end{array}$ & $\begin{array}{l}\text { Gallipoli, D., } \\
\text { Wheeler, S. \& } \\
\text { Karstunen, M. } \\
\text { (2003). Modelling } \\
\text { the variation of } \\
\text { degree of saturation } \\
\text { in a deformable } \\
\text { unsaturated soil. } \\
\text { Géotechnique } \mathbf{5 3} \text {, } \\
\text { No. 1, 105-112. }\end{array}$ & $\begin{array}{l}\text { Alonso, E. E., Gens, } \\
\text { A. \& Josa, A. } \\
\text { (1990). A } \\
\text { constitutive model } \\
\text { for partially } \\
\text { saturated soils. } \\
\text { Géotechnique 40, } \\
\text { No. 3, 405-430. }\end{array}$ & None & $\begin{array}{l}\text { Roscoe K.H. and } \\
\text { Burland J.B. On the } \\
\text { generalised stress- } \\
\text { strain behaviour of } \\
\text { wet clay. } \\
\text { Engineering } \\
\text { Plasticity (Heyman } \\
\text { J. and Leckie F.A. } \\
\text { (eds)). Cambridge } \\
\text { University Press, } \\
\text { Cambridge, 1968, } \\
\text { pp. 535-609. }\end{array}$ \\
\hline
\end{tabular}


D’Onza F. Gallipoli

D. and Wheeler S.

Gallipoli, D.,

Wheeler, S. \&

Karstunen, M. (2003). Modelling

UGLAS the variation of

2 degree of saturation

in a deformable

unsaturated soil.

Géotechnique 53,

No. 1, 105-112.
Effect of anisotropy

on the prediction of

unsaturated soil

response under

triaxial and

oedometric

conditions. Proc. 5th

Int. Conf. on

Unsaturated Soils

(Alonso E.E. and

Gens A. (eds)).

Balkema, Rotterdam, 2010, pp. 787-794.
Wheeler, S.,

Näätänen, A.,

Karstunen, M. \&

Lojander, M. (2003).

An anisotropic

elastoplastic model

for soft clays.

Canadian

Geotechnical

Journal 40, No.2,

403-418.
Gallipoli, D.,

Wheeler, S. \&

Karstunen, M. (2003). Modelling

the variation of

UNINA degree of saturation

in a deformable unsaturated soil. Géotechnique 53, No. 1, 105-112.
Wheeler, S. \&

Sivakumar, V. (1995). An elastoplastic critical state framework for unsaturated soil. Géotechnique 45, No. 1, 35-53.
The published version of the mechanical model has been extended by adding:

i) a Hvorslev surface of slope $h$ in the constant suction $q$ - $p^{\prime}$ plane to model peak strength on the dry side of the yield locus;

ii) a non-associated flow rule following the approach proposed by Cui and Delage (Cui and Delage, 1996) relating increments of plastic shear strain $\mathrm{d} \varepsilon_{s}^{p}$ and plastic volumetric strains $\mathrm{d} \varepsilon_{v}{ }^{p}$ as:

$\frac{\mathrm{d} \varepsilon_{s}^{p}}{\mathrm{~d} \varepsilon_{v}^{p}}=c_{1}+\frac{c_{2} \frac{q}{p_{0}}}{1-\frac{q}{M p+\mu}}$

Unlike others, this model does not assume any particular saturated parent formulation where $p_{0}, M$ and $\mu$ have the same meaning as in the work by Wheeler and Sivakumar (Wheeler and Sivakumar, 1995) while $c_{1}$ and $c_{2}$ are additional model parameters $\left(c_{2}\right.$ takes different values depending on whether the stress state is on the dry or wet side of the yield locus);

iii) an additional yield limit for suction increase similar to the existence of the SI yield curve in the BBM (Alonso et al., 1990).
Khalili, N., Habte, M.A. \& Zargarbashi, S. (2008). A fully coupled flow deformation

UNSW model for cyclic analysis of unsaturated soils including hydraulic and mechanical None hysteresis. Computers and Geotechnics 35, No.6, 872-889.
Khalili, N., Habte, M.A. \& Valliappan, S. (2005). A bounding surface plasticity model for cyclic loading of granular soils. International Journal for Numerical Methods in Eng. 63, No. 14, 1939-1960. 


\begin{tabular}{|c|c|c|c|c|}
\hline $\begin{array}{c}\text { Constitutive stress } \\
\text { Yield/bounding curve }\end{array}$ & (i) $\chi_{l}=0, \chi_{2}=0$ & (ii) $\chi_{I}=\chi_{I}(s), \chi_{2}=0$ & (iii) $\chi_{l}=\chi_{I}\left(S_{r}\right), \chi_{2}=0$ & (iv) $\chi_{I}=\chi_{I}\left(S_{r}\right), \chi_{2}=\chi_{I}\left(S_{r}\right)$ \\
\hline (a) $\omega_{l}=\omega_{l}(s)$ & (UNINA) & UNSW & EPFL & (ENPC) \\
\hline (b) $\omega_{l}=\omega_{l}(s)$ and $\omega_{2}=\omega_{2}(s)$ & $\begin{array}{c}\text { UGLAS-1 } \\
\text { UGLAS-2 } \\
\text { UNINA }\end{array}$ & CU & & \\
\hline (c) $\omega_{l}=\omega_{l}(s)$ and $\omega_{3}=\omega_{3}(s)$ & & & & ENPC \\
\hline
\end{tabular}

Table 2 - Mechanical models classification matrix

\begin{tabular}{|c|c|c|c|c|}
\hline Test code & Stress path & $\begin{array}{l}\text { Post- } \\
\text { compaction } \\
\text { void ratio }\end{array}$ & $\begin{array}{c}\text { Post- } \\
\text { compaction } \\
\text { degree of } \\
\text { saturation }\end{array}$ & Initial equalization \\
\hline \multicolumn{5}{|c|}{ Triaxial loading } \\
\hline TX03 & $\begin{array}{l}\text { Isotropic load } \\
(\eta=\Delta q / \Delta p=0) \\
\text { @ } s=200 \mathrm{kPa}\end{array}$ & 0.86 & 0.43 & $q=0 \mathrm{kPa}, p=20 \mathrm{kPa}, s=200 \mathrm{kPa}$ \\
\hline TX04 & $\begin{array}{c}\text { Anisotropic load } \\
(\eta=\Delta q / \Delta p=0.375) \\
@ s=200 \mathrm{kPa}\end{array}$ & 0.82 & 0.42 & $q=8 \mathrm{kPa}, p=20 \mathrm{kPa}, s=200 \mathrm{kPa}$ \\
\hline TX08 & $\begin{array}{c}\text { Anisotropic load } \\
(\eta=\Delta q / \Delta p=0.750) \\
@ @=200 \mathrm{kPa}\end{array}$ & 0.87 & 0.44 & $q=20 \mathrm{kPa}, p=27 \mathrm{kPa}, s=200 \mathrm{kPa}$ \\
\hline TX09 & $\begin{array}{l}\text { Anisotropic load } \\
(\eta=\Delta q / \Delta p=0.875) \\
\text { @ } \mathrm{s}=200 \mathrm{kPa}\end{array}$ & 0.81 & 0.42 & $q=19 \mathrm{kPa}, p=22 \mathrm{kPa}, s=200 \mathrm{kPa}$ \\
\hline \multicolumn{5}{|c|}{ Triaxial loading followed by shearing at constant radial net stress } \\
\hline TX01 & $\begin{array}{l}\text { No load } \\
\text { @ } s=200 \mathrm{kPa}\end{array}$ & 0.85 & 0.44 & $q=0 \mathrm{kPa}, p=10 \mathrm{kPa}, s=200 \mathrm{kPa}$ \\
\hline TX02 & $\begin{array}{l}\text { Isotropic load } \\
(\eta=\Delta q / \Delta p=0) \\
\text { @ } s=200 \mathrm{kPa}\end{array}$ & 0.83 & 0.43 & $q=0 \mathrm{kPa}, p=10 \mathrm{kPa}, s=200 \mathrm{kPa}$ \\
\hline TX06 & $\begin{array}{l}\text { Anisotropic load } \\
(\eta=\Delta q / \Delta p=0.750) \\
\text { @ } s=200 \mathrm{kPa}\end{array}$ & 0.83 & 0.40 & $q=15 \mathrm{kPa}, p=20 \mathrm{kPa}, s=200 \mathrm{kPa}$ \\
\hline TX07 & $\begin{array}{l}\text { Anisotropic load } \\
(\eta=\Delta q / \Delta p=0.750) \\
\quad @ s=200 \mathrm{kPa}\end{array}$ & 0.83 & 0.40 & $q=15 \mathrm{kPa}, p=20 \mathrm{kPa}, s=200 \mathrm{kPa}$ \\
\hline \multicolumn{5}{|c|}{ Ko loading } \\
\hline EDO-sat & Load/unload/reload@ saturation & 0.82 & 0.42 & $\sigma_{v}=1 \mathrm{kPa}, s=0 \mathrm{kPa}$ \\
\hline EDO-10 & Load/unload/reload @ $s=10 \mathrm{kPa}$ & 0.82 & 0.38 & $\sigma_{v}=20 \mathrm{kPa}, s=10 \mathrm{kPa}$ \\
\hline EDO-50 & Load/unload/reload @ $s=50 \mathrm{kPa}$ & 0.82 & 0.41 & $\sigma_{v}=20 \mathrm{kPa}, s=50 \mathrm{kPa}$ \\
\hline EDO-100 & Load/unload/reload @ $s=100 \mathrm{kPa}$ & 0.82 & 0.41 & $\sigma_{v}=20 \mathrm{kPa}, s=100 \mathrm{kPa}$ \\
\hline EDO-200 & $\begin{array}{c}\text { Wet/dry @ } \sigma_{\mathrm{v}}=20 \mathrm{kPa} \\
\text { Load/unload/reload @ } s=200 \mathrm{kPa} \\
\text { Wet/dry @ } \sigma_{\mathrm{v}}=800 \mathrm{kPa}\end{array}$ & 0.81 & 0.38 & $\sigma_{v}=20 \mathrm{kPa}, s=200 \mathrm{kPa}$ \\
\hline
\end{tabular}

Table 3 - Summary of tests used during calibration of constitutive models 


\begin{tabular}{|c|c|c|c|c|}
\hline \multirow{2}{*}{ Team } & \multicolumn{2}{|c|}{ Mechanical model parameters } & \multicolumn{2}{|c|}{ Water retention model parameters } \\
\hline & Symbol and units & Value & Symbol and units & Value \\
\hline \multirow{9}{*}{$\mathrm{CU}$} & $\phi_{c}\left({ }^{\circ}\right)$ & 36.0 & $s_{e 0}(\mathrm{kPa})$ & 10 \\
\hline & $\lambda^{*}(-)$ & 0.09 & $\lambda_{p 0}(-)$ & 0.25 \\
\hline & $\kappa^{*}(-)$ & 0.0025 & $e_{0}(-)$ & 0.7 \\
\hline & $N(-)$ & 0.925 & & \\
\hline & $r(-)$ & 0.03 & & \\
\hline & $n(-)$ & 0.055 & & \\
\hline & $l(-)$ & 0 & & \\
\hline & $m(-)$ & 2 & & \\
\hline & Saturated Hvorslev stress $(\mathrm{kPa})$ & 33.3 & & \\
\hline \multirow{16}{*}{ ENPC } & $K_{0}^{e}(\mathrm{kPa})$ & 15000 & $s_{e 0}(\mathrm{kPa})$ & 5.0 \\
\hline & $n(-)$ & 0.6 & $\lambda_{0}(-)$ & 3.78 \\
\hline & $v(-)$ & 0.35 & $A(-)$ & 16.0 \\
\hline & $K_{0}^{p}(\mathrm{kPa})$ & 600 & $\phi_{\text {ref }}(-)$ & 0.465 \\
\hline & $\gamma(-)$ & 0.8 & & \\
\hline & $a\left(\mathrm{kPa}^{-1}\right)$ & 0.021 & & \\
\hline & $\phi_{0}(-)$ & 7.05 & & \\
\hline & $\beta_{0}(-)$ & -0.08 & & \\
\hline & $R_{e}(-)$ & 0.1 & & \\
\hline & $R_{c}(-)$ & 0.6 & & \\
\hline & $k_{l}(-)$ & 0.3 & & \\
\hline & $k_{2}(-)$ & 0 & & \\
\hline & $k_{3}(-)$ & 0 & & \\
\hline & $k_{4}(-)$ & 0 & & \\
\hline & $Q_{0}(\mathrm{kPa})$ & 47 & & \\
\hline & $X(-)$ & Null tensor & & \\
\hline \multirow{15}{*}{ EPFL } & $K_{i}(\mathrm{kPa})$ & 150000 & $K_{h}(-)$ & 18 \\
\hline & $G_{i}(\mathrm{kPa})$ & 120000 & $\beta_{h}(-)$ & 10 \\
\hline & $n^{e}(-)$ & 1 & $s_{e}(\mathrm{kPa})$ & 3 \\
\hline & $\phi^{\prime}\left({ }^{\circ}\right)$ & 31.0 & $\pi_{H}(\mathrm{kPa})$ & 350 \\
\hline & $\beta_{0}(-)$ & 17 & $s_{D I}(\mathrm{kPa})$ & 15 \\
\hline & $\alpha(-)$ & 0.75 & $S_{\text {res }}(-)$ & 0.01 \\
\hline & $a(-)$ & 0.02 & & \\
\hline & $b(-)$ & 0.01 & & \\
\hline & $c(-)$ & 0.0001 & & \\
\hline & $d(-)$ & 2 & & \\
\hline & $r_{d e v}^{e}(-)$ & 0.01 & & \\
\hline & $r_{i s o}^{e}(-)$ & 0.1 & & \\
\hline & $\gamma_{s}(-)$ & 1.8 & & \\
\hline & $\Omega(-)$ & $2 e-5$ & & \\
\hline & $p_{\mathrm{CR}}^{\prime}(\mathrm{kPa})$ & 27 & & \\
\hline \multirow{11}{*}{ UGLAS 1} & $\kappa(-)$ & 0.004 & $\phi\left(\mathrm{kPa}^{-1}\right)$ & 1.318 \\
\hline & $\kappa_{s}(-)$ & 0.006 & $\psi(-)$ & 6.036 \\
\hline & $G(\mathrm{kPa})$ & 36000 & $m(-)$ & 0.146 \\
\hline & $N(0)$ at $p^{\prime}=p_{c}(-)$ & -0.4928 & $n(-)$ & 1.341 \\
\hline & $\lambda(0)(-)$ & 0.1358 & & \\
\hline & $r(-)$ & 1.19597 & & \\
\hline & $\beta\left(\mathrm{kPa}^{-1}\right)$ & 0.00397 & & \\
\hline & $p_{c}(\mathrm{kPa})$ & 826699057 & & \\
\hline & $k(-)$ & 0.138 & & \\
\hline & $M(-)$ & 1.45 & & \\
\hline & $p_{o}^{*}(\mathrm{kPa})$ & 30 & & \\
\hline
\end{tabular}




\begin{tabular}{|c|c|c|c|c|}
\hline \multirow{14}{*}{ UGLAS 2} & $\kappa(-)$ & 0.004 & $\phi\left(\mathrm{kPa}^{-1}\right)$ & 1.318 \\
\hline & $\kappa_{s}(-)$ & 0.006 & $\psi(-)$ & 6.036 \\
\hline & $G(\mathrm{kPa})$ & 36000 & $m(-)$ & 0.146 \\
\hline & $N(0)$ at $p^{\prime}=p_{c}(-)$ & -0.42641 & $n(-)$ & 1.341 \\
\hline & $\lambda(0)(-)$ & 0.1358 & & \\
\hline & $r(-)$ & 1.19597 & & \\
\hline & $\beta\left(\mathrm{kPa}^{-1}\right)$ & 0.00397 & & \\
\hline & $p_{c}(\mathrm{kPa})$ & 508841924 & & \\
\hline & $k(-)$ & 0.138 & & \\
\hline & $M(-)$ & 1.45 & & \\
\hline & $\mu(-)$ & 92.047 & & \\
\hline & $b(-)$ & 1 & & \\
\hline & $\bar{~} p_{m}(0)(\mathrm{kPa})$ & 30 & & \\
\hline & $\alpha$ & 0.144 & & \\
\hline \multirow{16}{*}{ UNINA } & $\kappa(-)$ & 0.003 & $\phi\left(\mathrm{kPa}^{-1}\right)$ & 0.51 \\
\hline & $\kappa_{S}(-)$ & 0.003 & $\psi(-)$ & 4.81 \\
\hline & $\lambda_{s}(-)$ & 0.09 & $m(-)$ & 0.22 \\
\hline & $G(\mathrm{kPa})$ & 5000 & $n(-)$ & 1.04 \\
\hline & $h(-)$ & 1.2 & & \\
\hline & $c_{l}(-)$ & -0.2 & & \\
\hline & $c_{2}$ wet side (-) & 0.5 & & \\
\hline & $c_{2}$ dry side (-) & 0.1 & & \\
\hline & $\lambda(-)$ & $0.130 / 0.130^{*}$ & & \\
\hline & $N(-)$ & $1.753 / 1.880^{*}$ & & \\
\hline & $M(-)$ & $1.455 / 1.455^{*}$ & & \\
\hline & $\mu(\mathrm{kPa})$ & $0 / 40^{*}$ & & \\
\hline & $\Psi(-)$ & $0.130 / 0.100^{*}$ & & \\
\hline & $\Gamma(-)$ & $1.665 / 1.820^{*}$ & & \\
\hline & $p_{o}(0)(\mathrm{kPa})$ & 52 & & \\
\hline & $*$ the two values refer to $s=0$ and $200 \mathrm{k}$ & Pa respectively (linear & ation was use & liate suctions) \\
\hline \multirow{10}{*}{ UNSW } & $\kappa(-)$ & 0.0004 & $s_{e x}(\mathrm{kPa})$ & 5.0 \\
\hline & $v(-)$ & 0.30 & $s_{a e}(\mathrm{kPa})$ & 15.0 \\
\hline & $\phi_{c}{ }^{\prime}\left({ }^{\circ}\right)$ & 35.9 & $\lambda_{p}(-)$ & 0.24 \\
\hline & $\lambda(-)$ & 0.16 for $s \geq s_{e x}$ or $s_{a e}$ & $\xi(-)$ & 0.08 \\
\hline & $N(-)$ & $\begin{array}{l}2.67 \text { for } s \geq 100 \mathrm{kPa} \\
2.62 \text { for } s=50 \mathrm{kPa} \\
2.56 \text { for } s \leq s_{e x} \text { or } s_{a e}\end{array}$ & $\zeta(-)$ & 0.2 \\
\hline & N (-) & 2.25 & & \\
\hline & $R(-)$ & 1.40 & & \\
\hline & $A(-)$ & 1.0 & & \\
\hline & $k_{m}(-)$ & 20.0 & & \\
\hline & Isotropic saturated yield stress $(\mathrm{kPa})$ & 98.7 & & \\
\hline
\end{tabular}

Table 4 - Model parameter values used by participating teams (figures below double line represent initial values of state variables) 


\section{FIGURES CAPTIONS}


Figure 1 - Grading curve of Jossigny silt

Figure 2 - Stress paths for tests involving triaxial compression: TX03 - isotropic compression until a mean net stress of $260 \mathrm{kPa}$, TX04 - anisotropic compression $(\eta=$ $0.375)$ until a mean net stress of $285 \mathrm{kPa}$, TX08 - anisotropic compression $(\eta=0.750)$ until a mean net stress of $370 \mathrm{kPa}$ and TX09 - anisotropic compression $(\eta=0.875)$ until a mean net stress of $370 \mathrm{kPa}$

Figure 3 - Stress paths for tests involving triaxial compression followed by shearing: a) TX01 - shearing to critical state (no compression) and TX02 - isotropic compression until a mean net stress of $20 \mathrm{kPa}$ followed by shearing to critical state, $\mathrm{b}$ ) TX06 - anisotropic compression $(\eta=0.750)$ until a mean net stress of $100 \mathrm{kPa}$ followed by shearing to critical state and TX07 - anisotropic compression $(\eta=0.750)$ until a mean net stress of $200 \mathrm{kPa}$ followed by shearing to critical state

Figure 4 - Stress paths for tests involving Ko loading: a) EDO-sat - loading to a vertical effective stress of $800 \mathrm{kPa}$, unloading to $100 \mathrm{kPa}$ and reloading to $1600 \mathrm{kPa}$, b) EDO-10 - loading to a vertical net stress of $800 \mathrm{kPa}$, unloading to $100 \mathrm{kPa}$ and reloading to $1200 \mathrm{kPa}, \mathrm{c})$ EDO-50 - loading to a vertical net stress of $800 \mathrm{kPa}$, unloading to $100 \mathrm{kPa}$ and reloading to $1226 \mathrm{kPa}$, d) EDO-100 - loading to a vertical net stress of $800 \mathrm{kPa}$, unloading to $100 \mathrm{kPa}$ and reloading to $1080 \mathrm{kPa}$ and e) EDO200 - wetting to a suction of 10 , drying to $200 \mathrm{kPa}$, loading to a vertical net stress of $800 \mathrm{kPa}$, unloading to $100 \mathrm{kPa}$, reloading to $800 \mathrm{kPa}$, wetting to a suction of 55 and drying to $200 \mathrm{kPa}$

Figure 5 - Stress paths for the blind test involving isotropic compression until a mean net stress of $150 \mathrm{kPa}$ followed by shearing to critical state at constant water content

Figure 6 - Predicted and experimental behaviour during shearing stage of test TX02: a) deviator stress $(q)$ versus axial strain $\left(\varepsilon_{a}\right)$, b) volumetric strain $\left(\varepsilon_{v}\right)$ versus axial strain $\left(\varepsilon_{a}\right)$, c) degree of saturation $\left(S_{r}\right)$ versus volumetric strain $\left(\varepsilon_{v}\right)$ and d) degree of saturation $\left(S_{r}\right)$ versus axial strain $\left(\varepsilon_{a}\right)$ 
Figure 7 - Predicted and experimental behaviour during loading stage of test TX07: a) void ratio $(e)$ versus mean net stress $(p)$ and b) degree of saturation $\left(S_{r}\right)$ versus void ratio $(e)$ and c) degree of saturation $\left(S_{r}\right)$ versus mean net stress $(p)$

Figure 8 - Predicted and experimental behaviour during shearing stage of test TX07: a) deviator stress $(q)$ versus axial strain $\left(\varepsilon_{a}\right)$, b) volumetric strain $\left(\varepsilon_{v}\right)$ versus axial strain $\left(\varepsilon_{a}\right)$, c) degree of saturation $\left(S_{r}\right)$ versus volumetric strain $\left(\varepsilon_{v}\right)$ and d) degree of saturation $\left(S_{r}\right)$ versus axial strain $\left(\varepsilon_{a}\right)$

Figure 9 - Predicted and experimental behaviour during loading stage of blind test: a) void ratio $(e)$ versus mean net stress $(p)$, b) degree of saturation $\left(S_{r}\right)$ versus void ratio $(e)$ and c) degree of saturation $\left(S_{r}\right)$ versus mean net stress $(p)$

Figure 10 - Predicted and experimental behaviour during shearing stage of blind test: a) deviator stress $(q)$ versus axial strain $\left(\varepsilon_{a}\right)$, b) volumetric strain $\left(\varepsilon_{v}\right)$ versus axial strain $\left(\varepsilon_{a}\right)$, c) degree of saturation $\left(S_{r}\right)$ versus volumetric strain $\left(\varepsilon_{v}\right)$, d) degree of saturation $\left(S_{r}\right)$ versus axial strain $\left(\varepsilon_{a}\right)$ and e) suction $(s)$ versus axial strain $\left(\varepsilon_{a}\right)$

Figure 11 - Predicted and experimental behaviour during first wetting-drying cycle of test EDO-200: a) variation of degree of saturation $\left(S_{r}\right)$ versus suction $(s)$ for hysteretic water retention models (EPFL and UNSW) and b) variation of degree of saturation $\left(S_{r}\right)$ versus suction $(s)$ for non-hysteretic water retention models (CU, ENPC, UGLAS-1, UGLAS-2 and UNINA)

Figure 12 - Predicted and experimental behaviour during loading-unloading-reloading cycle of test EDO-200: a) variation of void ratio $(e)$ versus vertical net stress $\left(\sigma_{v}\right)$ and b) variation of degree of saturation $\left(S_{r}\right)$ versus vertical net stress $\left(\sigma_{v}\right)$

Figure 13 - Predicted and experimental behaviour during second wetting-drying cycle of test EDO-200: a) variation of void ratio $(e)$ versus suction $(s)$, b) variation of degree of saturation $\left(S_{r}\right)$ versus suction $(s)$ for hysteretic water retention models (EPFL and UNSW) and c) variation of degree of saturation $\left(S_{r}\right)$ versus suction $(s)$ for non-hysteretic water retention models (CU, ENPC, UGLAS-1, UGLAS-2 and UNINA) 


\section{FIGURES}

Page 57 of 78 


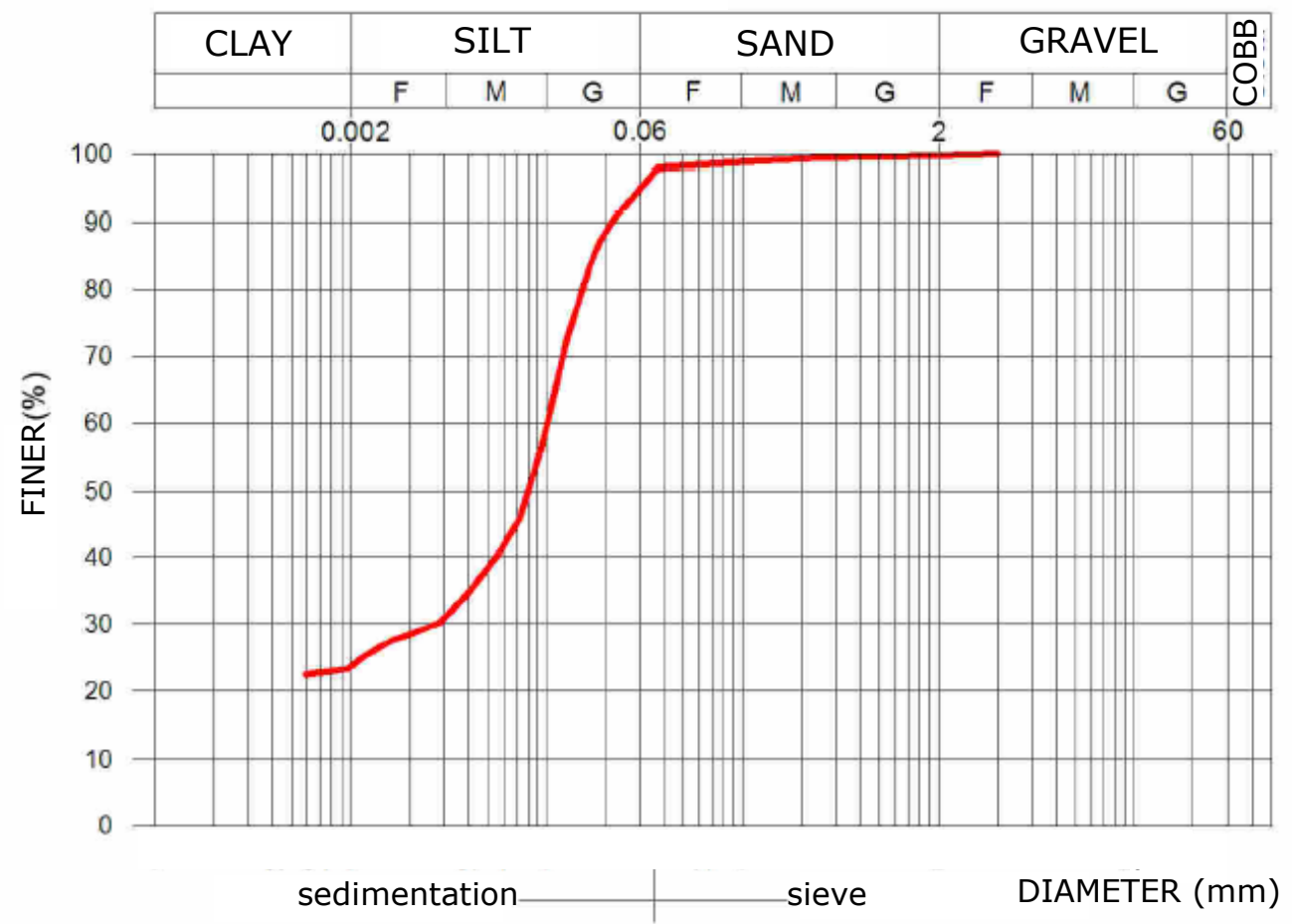

Figure 1 - Grading curve of Jossigny silt 




Figure 2 - Stress paths for tests involving triaxial compression: TX03 - isotropic compression until a mean net stress of $260 \mathrm{kPa}$, TX04 - anisotropic compression $(\eta=$ $0.375)$ until a mean net stress of $285 \mathrm{kPa}$, TX08 - anisotropic compression $(\eta=0.750)$ until a mean net stress of $370 \mathrm{kPa}$ and TX09 - anisotropic compression $(\eta=0.875)$ until a mean net stress of $370 \mathrm{kPa}$. 


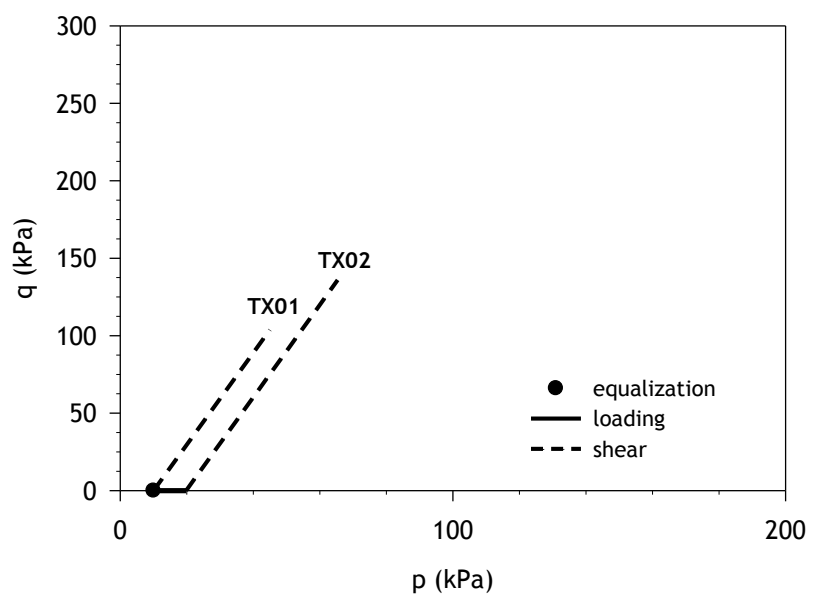

a)



b)

Figure 3 - Stress paths for tests involving triaxial compression followed by shearing: a) TX01 - shearing to critical state (no compression) and TX02 - isotropic compression until a mean net stress of $20 \mathrm{kPa}$ followed by shearing to critical state, b) TX06 - anisotropic compression $(\eta=0.750)$ until a mean net stress of $100 \mathrm{kPa}$ followed by shearing to critical state and TX07 - anisotropic compression $(\eta=0.750)$ until a mean net stress of $200 \mathrm{kPa}$ followed by shearing to critical state 


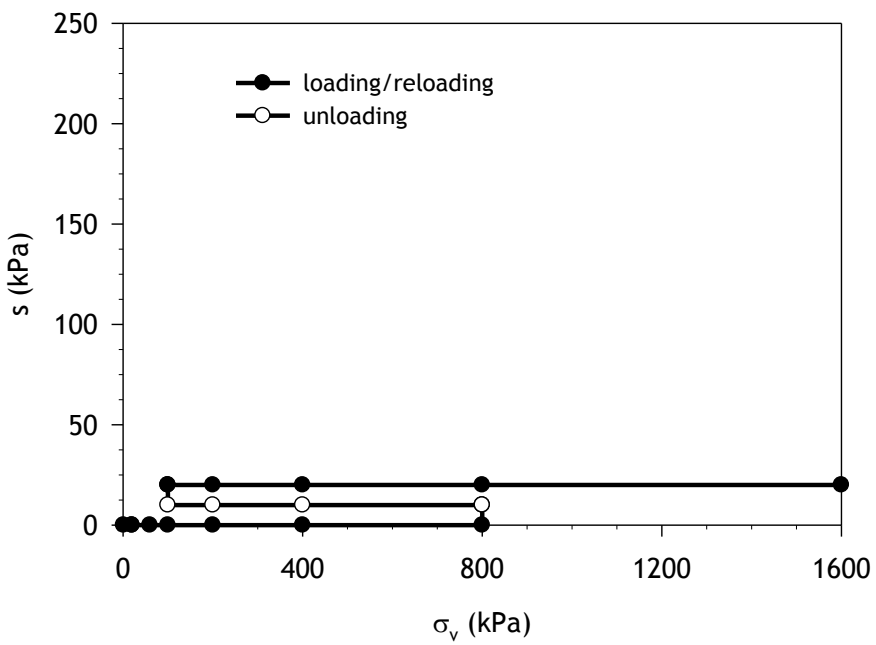

a)

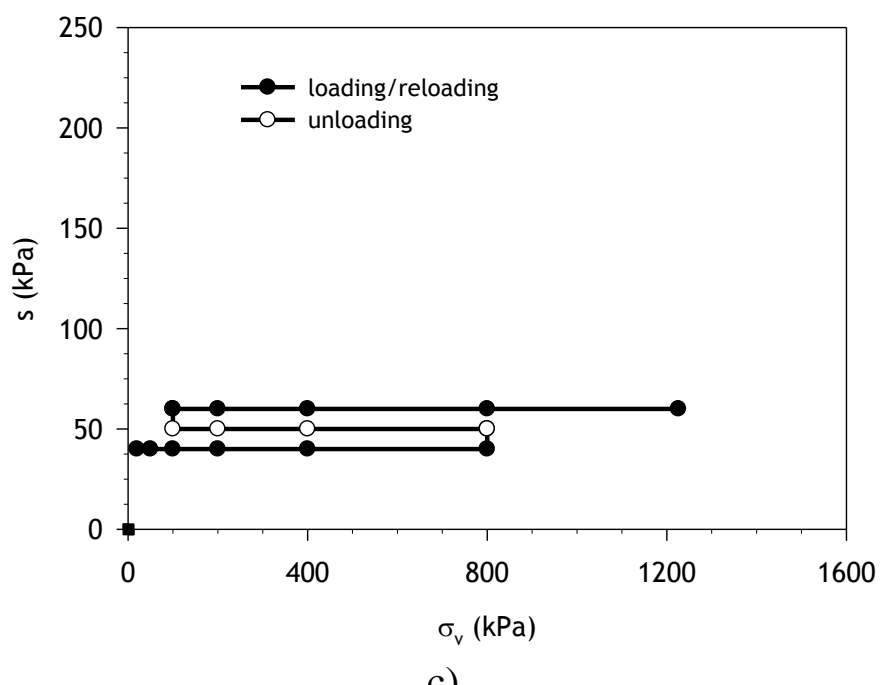

c)

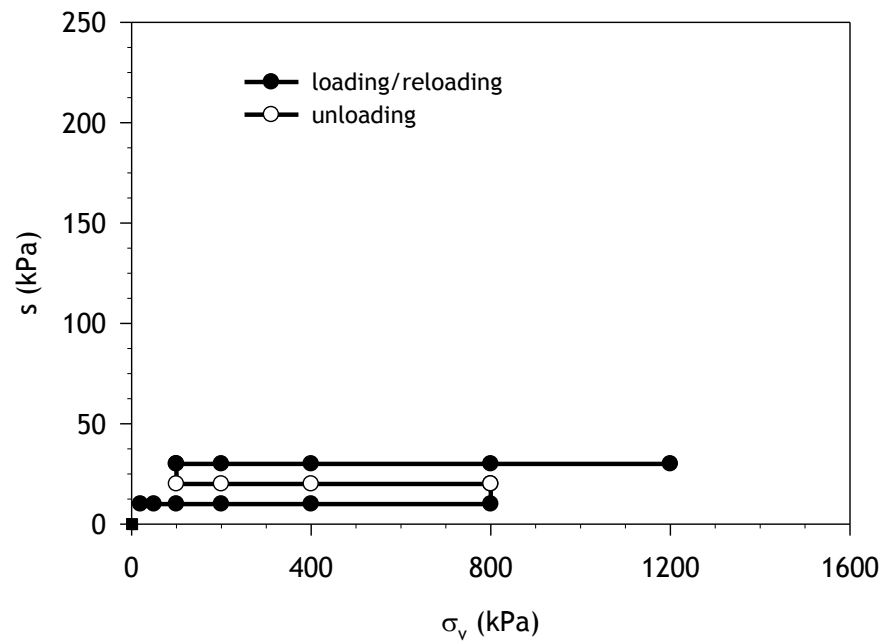

b)

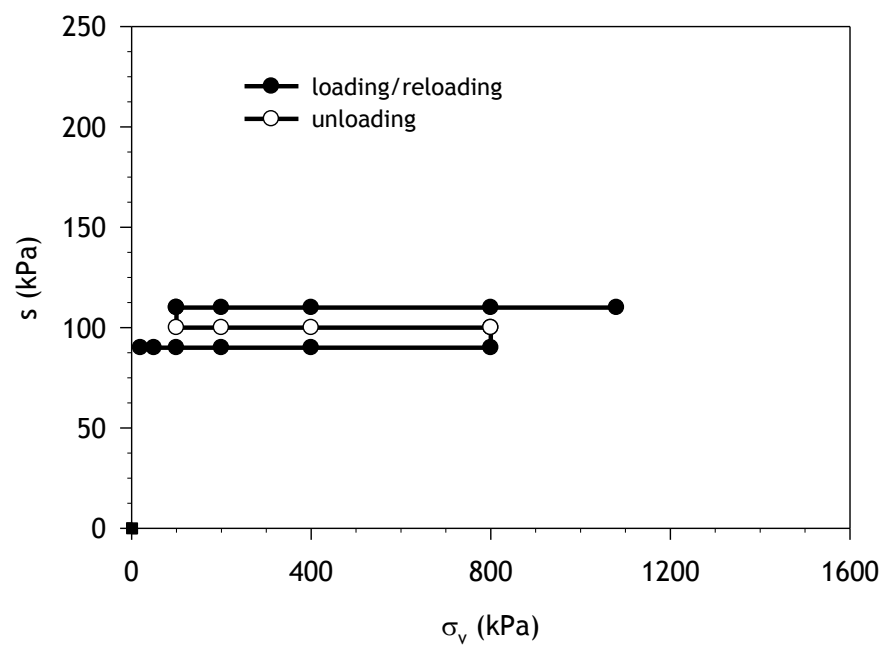

d)

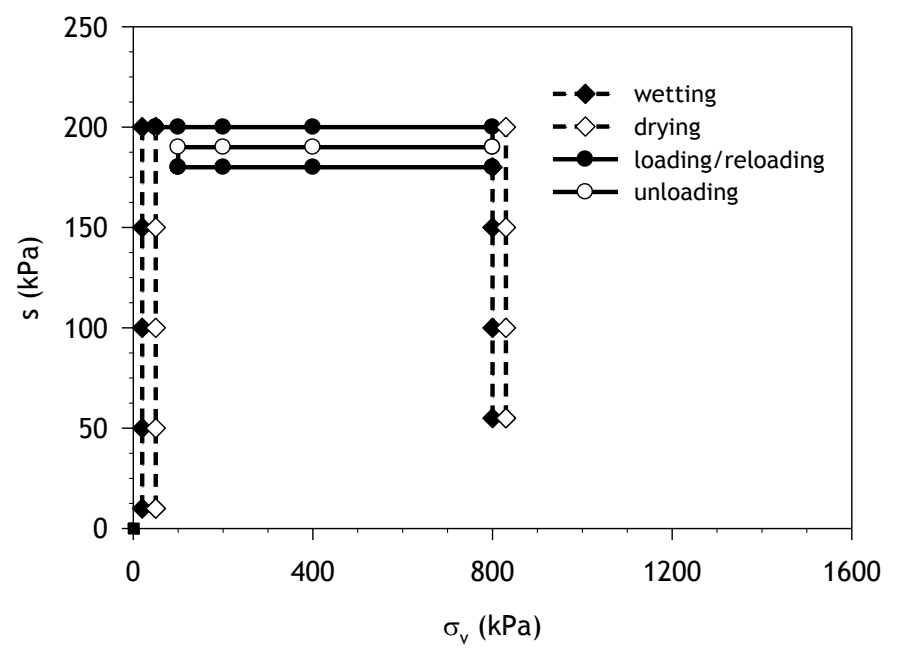

e) 
Figure 4 - Stress paths for tests involving Ko loading: a) EDO-sat - loading to a vertical effective stress of $800 \mathrm{kPa}$, unloading to $100 \mathrm{kPa}$ and reloading to $1600 \mathrm{kPa}$, b) EDO-10 - loading to a vertical net stress of $800 \mathrm{kPa}$, unloading to $100 \mathrm{kPa}$ and reloading to $1200 \mathrm{kPa}$, c) EDO-50 - loading to a vertical net stress of $800 \mathrm{kPa}$, unloading to $100 \mathrm{kPa}$ and reloading to $1226 \mathrm{kPa}$, d) EDO-100 - loading to a vertical net stress of $800 \mathrm{kPa}$, unloading to $100 \mathrm{kPa}$ and reloading to $1080 \mathrm{kPa}$ and e) EDO200 - wetting to a suction of 10 , drying to $200 \mathrm{kPa}$, loading to a vertical net stress of $800 \mathrm{kPa}$, unloading to $100 \mathrm{kPa}$, reloading to $800 \mathrm{kPa}$, wetting to a suction of 55 and drying to $200 \mathrm{kPa}$ 




Figure 5 - Stress paths for the blind test involving isotropic compression until a mean net stress of $150 \mathrm{kPa}$ followed by shearing to critical state at constant water content 


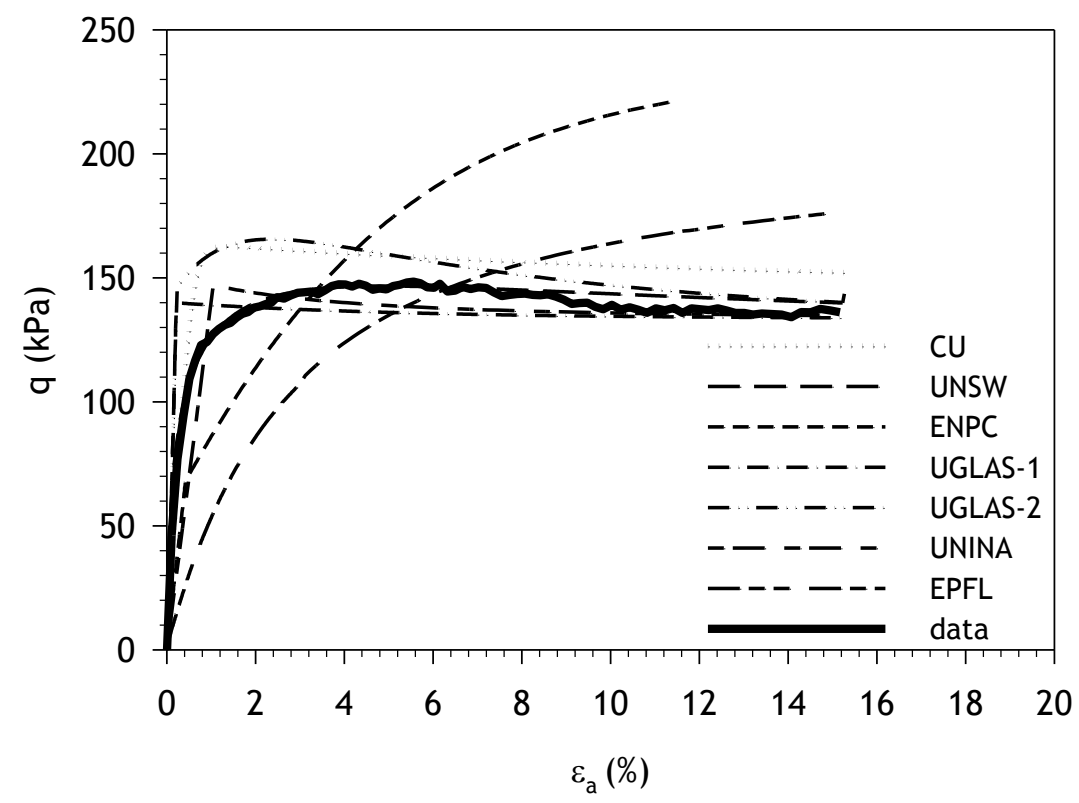

a)

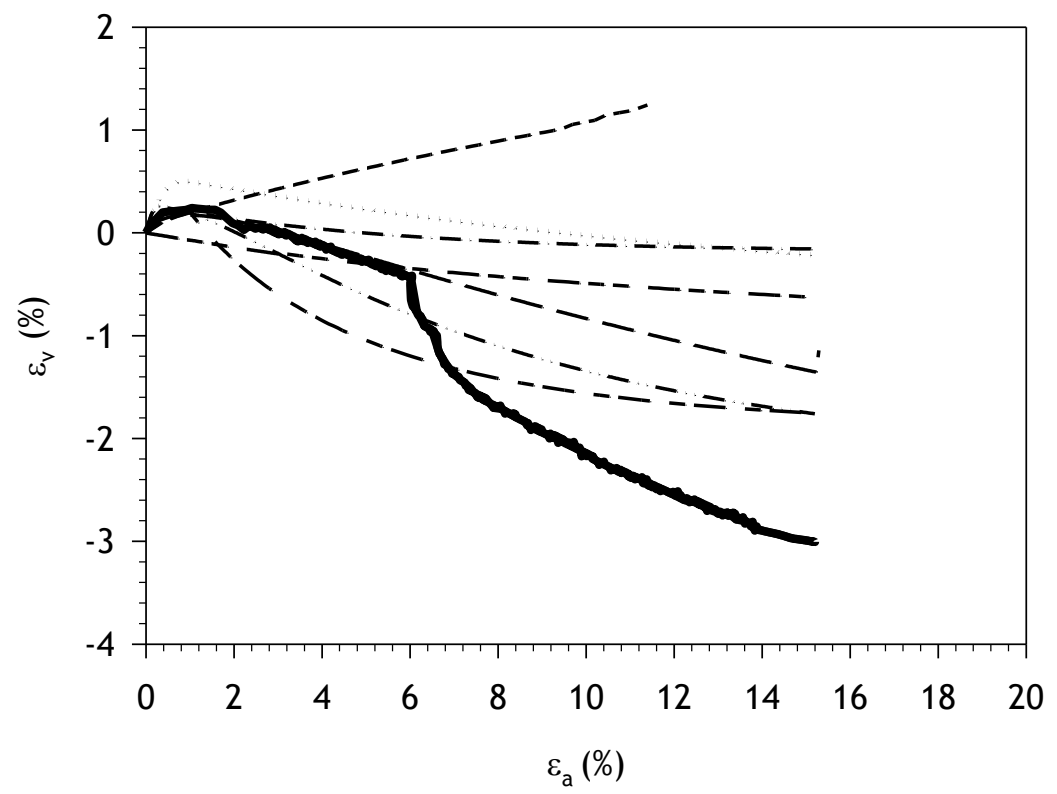

b) 


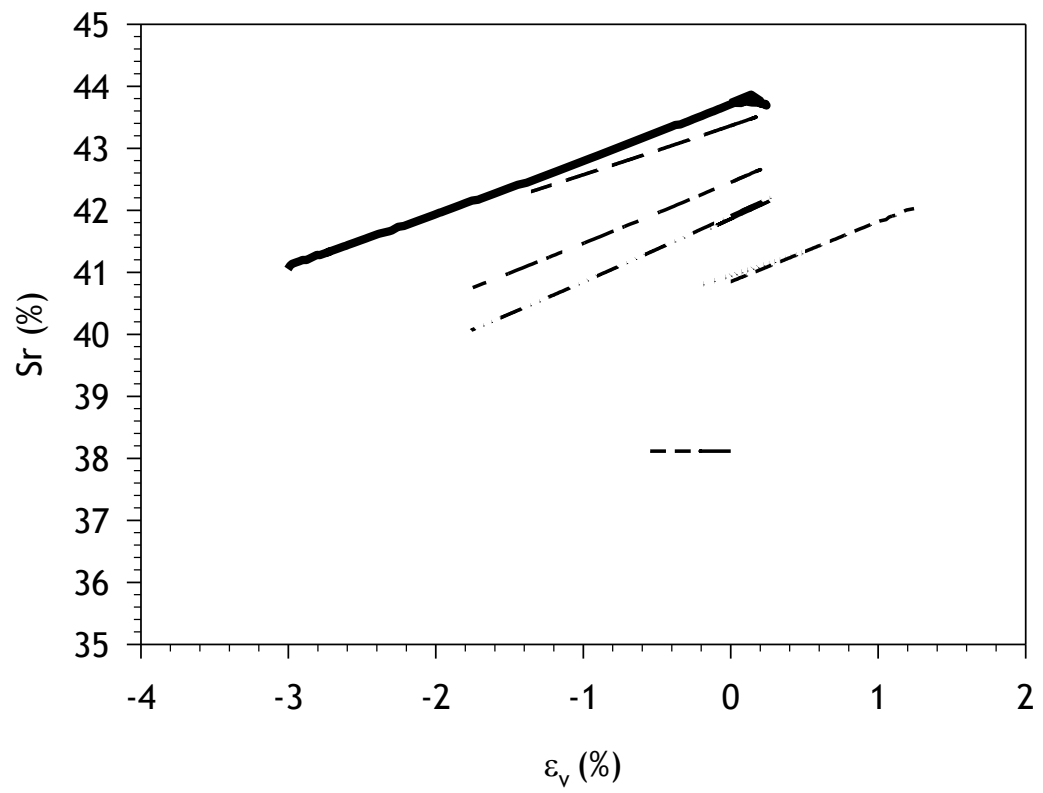

c)

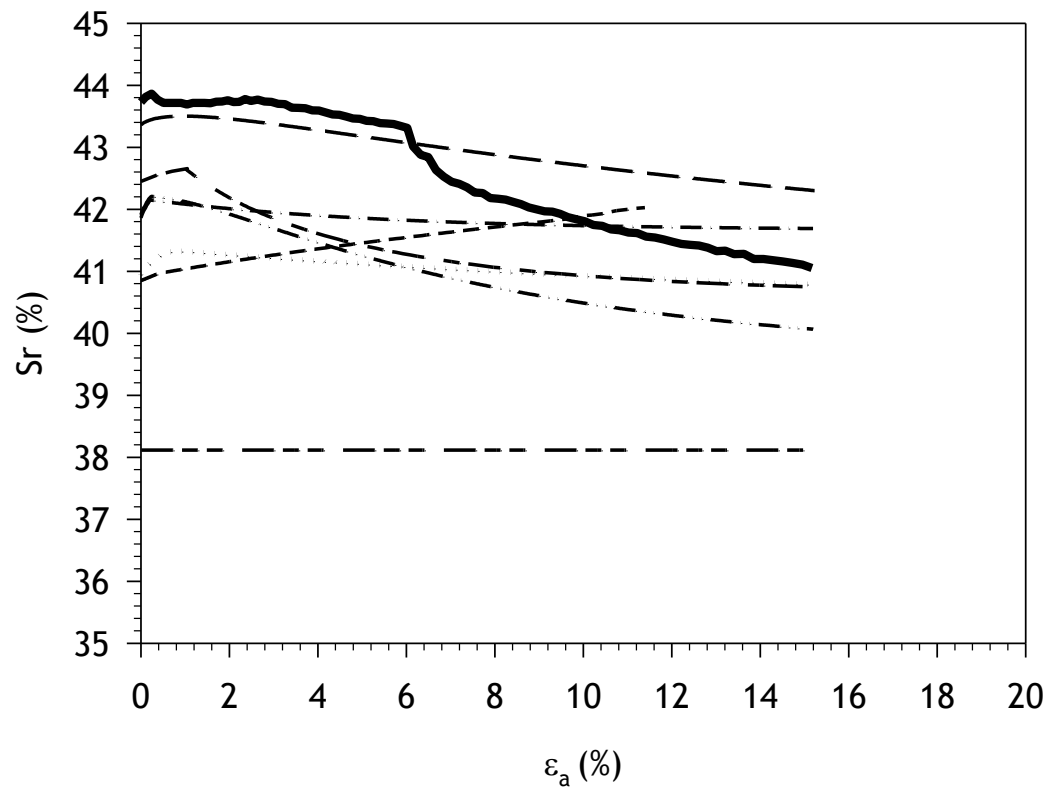

d)

Figure 6 - Predicted and experimental behaviour during shearing stage of test TX02: a) deviator stress $(q)$ versus axial strain $\left(\varepsilon_{a}\right)$, b) volumetric strain $\left(\varepsilon_{v}\right)$ versus axial strain $\left(\varepsilon_{a}\right)$, c) degree of saturation $\left(S_{r}\right)$ versus volumetric strain $\left(\varepsilon_{v}\right)$ and d) degree of saturation $\left(S_{r}\right)$ versus axial strain $\left(\varepsilon_{a}\right)$ 




a)

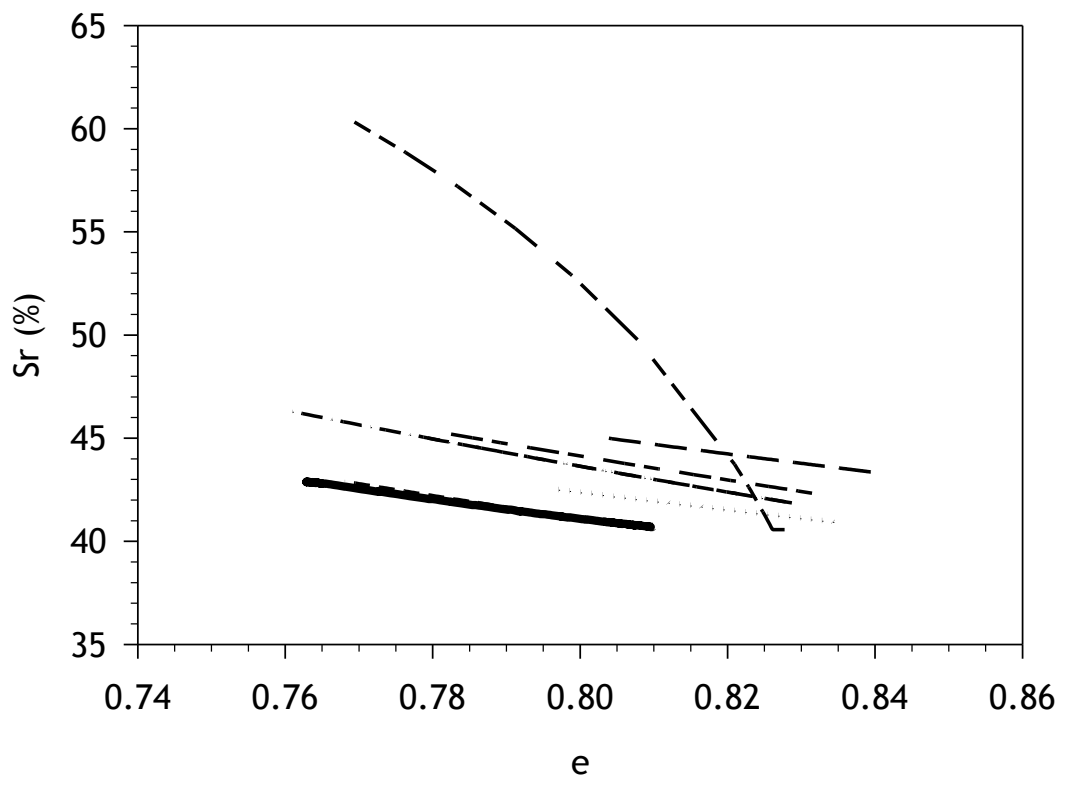

b) 


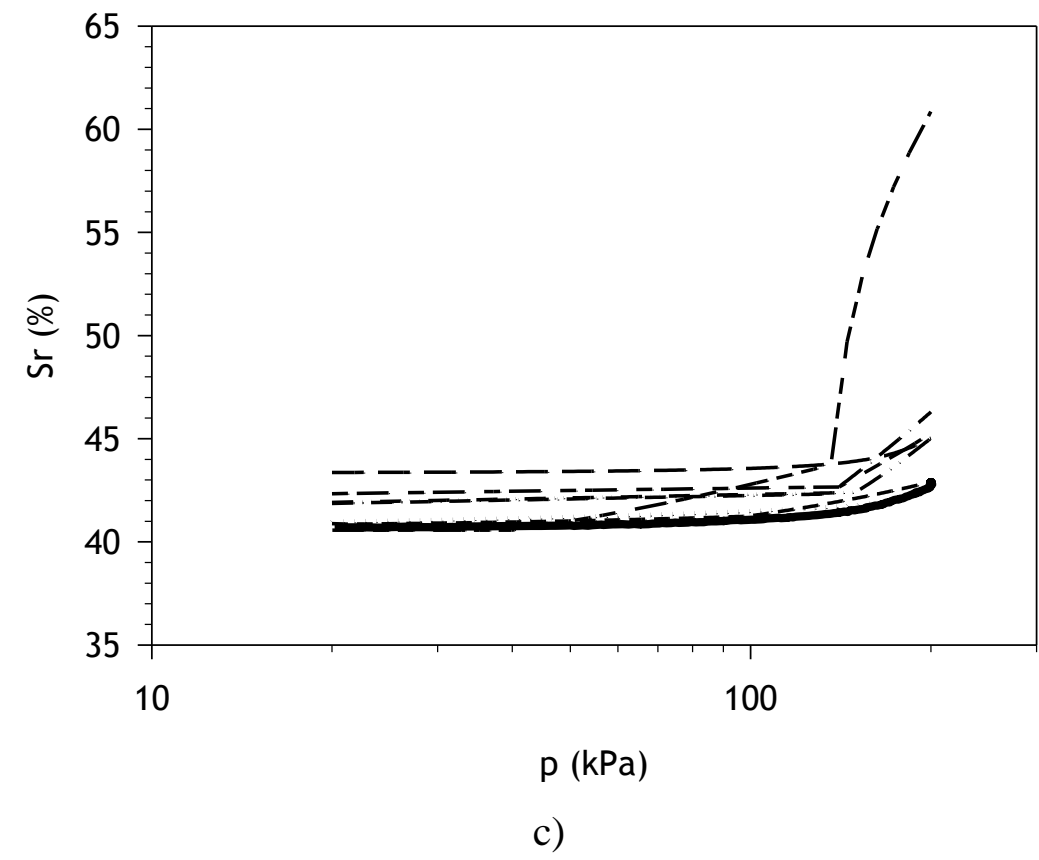

Figure 7 - Predicted and experimental behaviour during loading stage of test TX07: a) void ratio $(e)$ versus mean net stress $(p)$, b) degree of saturation $\left(S_{r}\right)$ versus void ratio (e) and c) degree of saturation $\left(S_{r}\right)$ versus mean net stress $(p)$ 


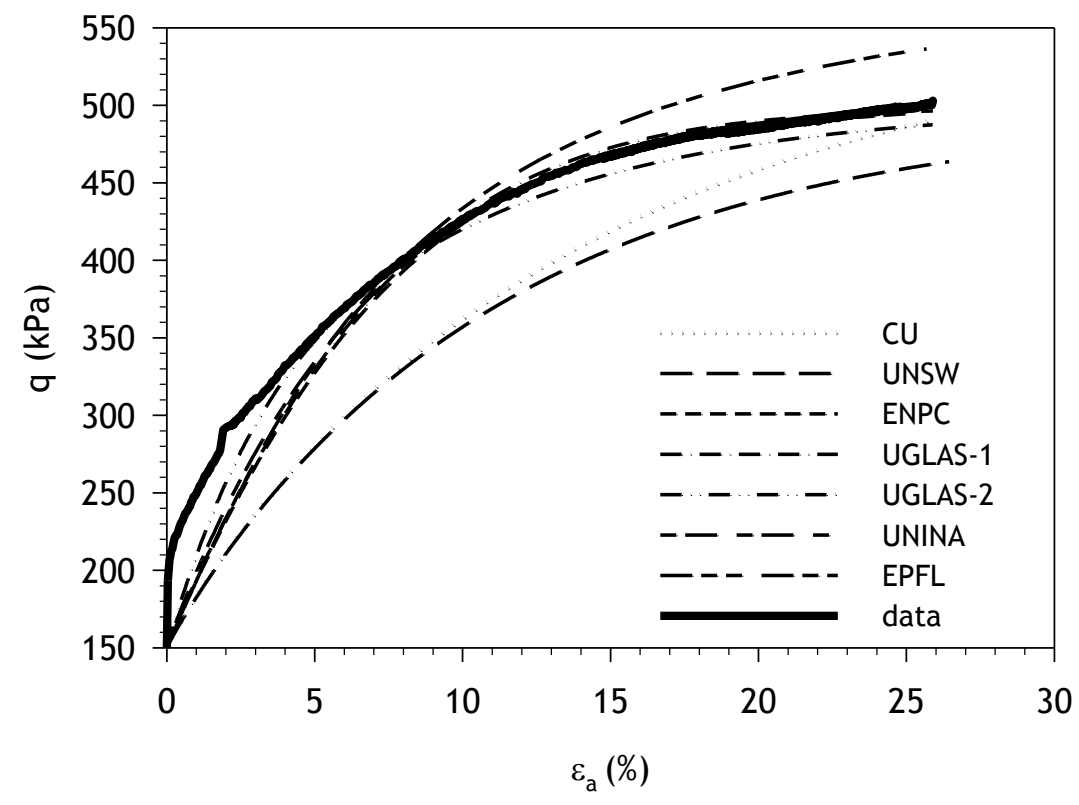

a)

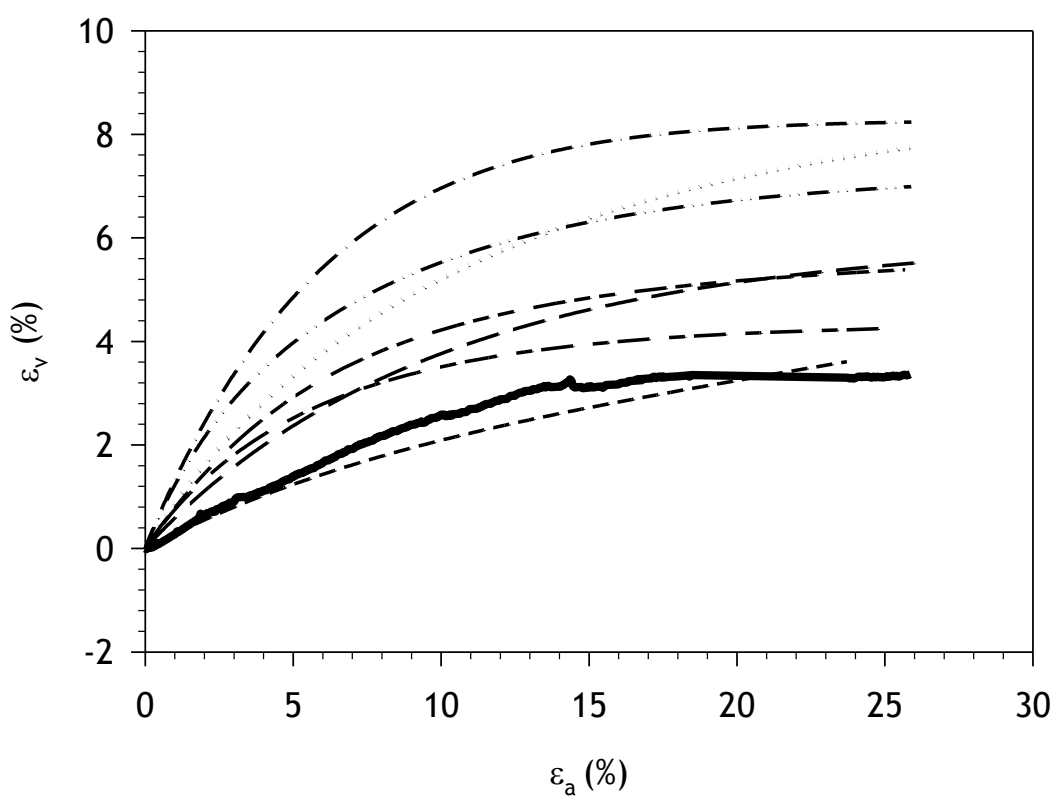

b) 

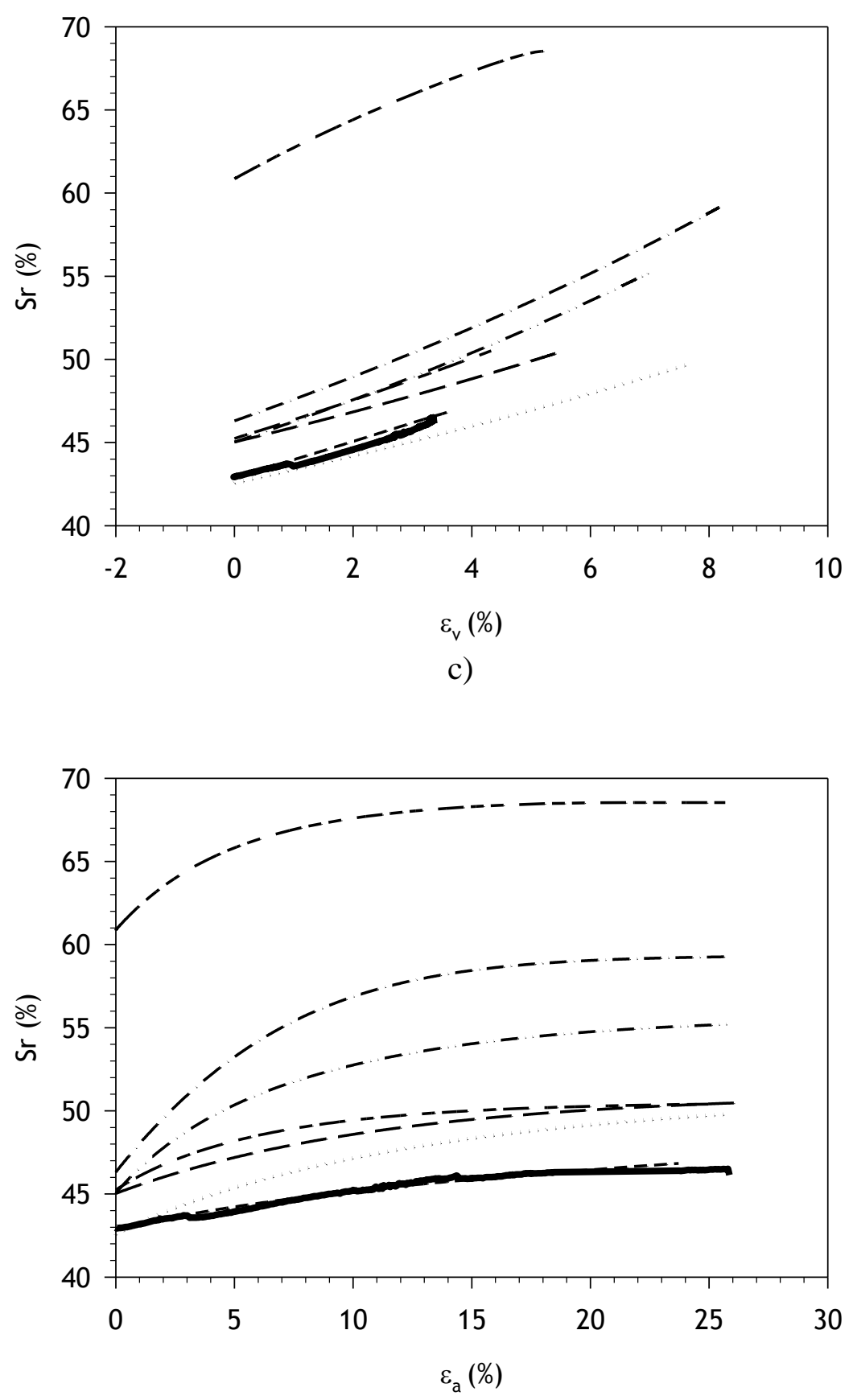

d)

Figure 8 - Predicted and experimental behaviour during shearing stage of test TX07: a) deviator stress $(q)$ versus axial strain $\left(\varepsilon_{a}\right)$, b) volumetric strain $\left(\varepsilon_{v}\right)$ versus axial strain $\left(\varepsilon_{a}\right)$, c) degree of saturation $\left(S_{r}\right)$ versus volumetric strain $\left(\varepsilon_{v}\right)$ and d) degree of saturation $\left(S_{r}\right)$ versus axial strain $\left(\varepsilon_{a}\right)$ 


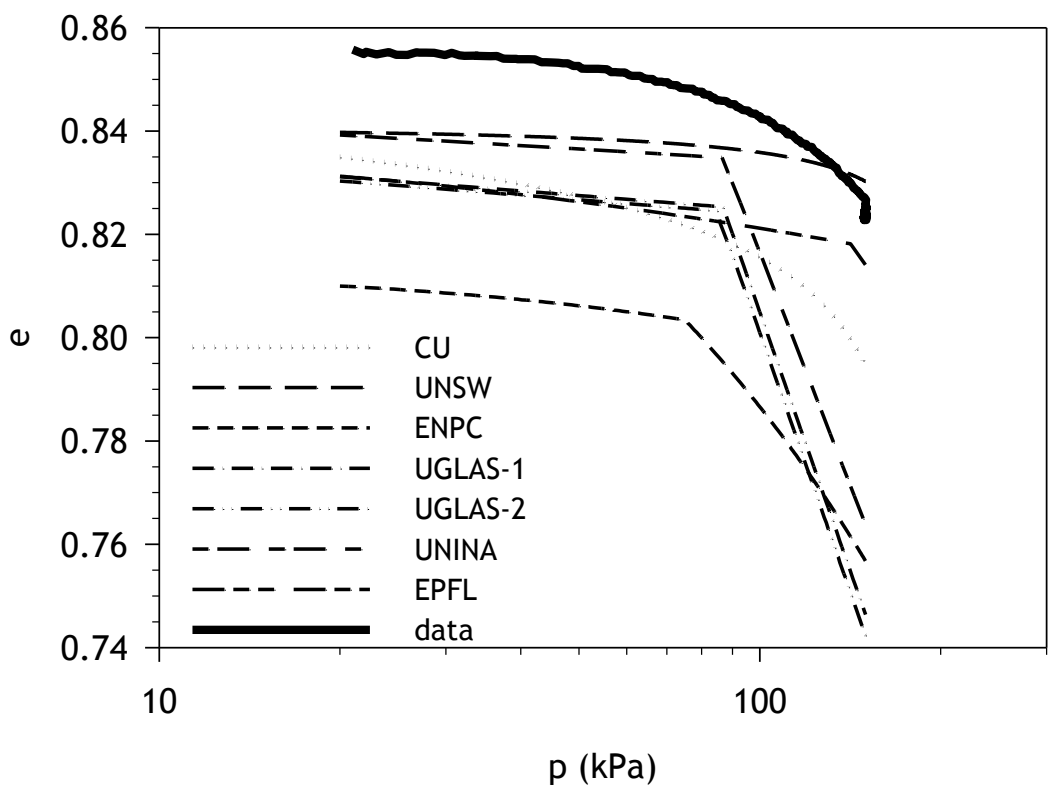

a)

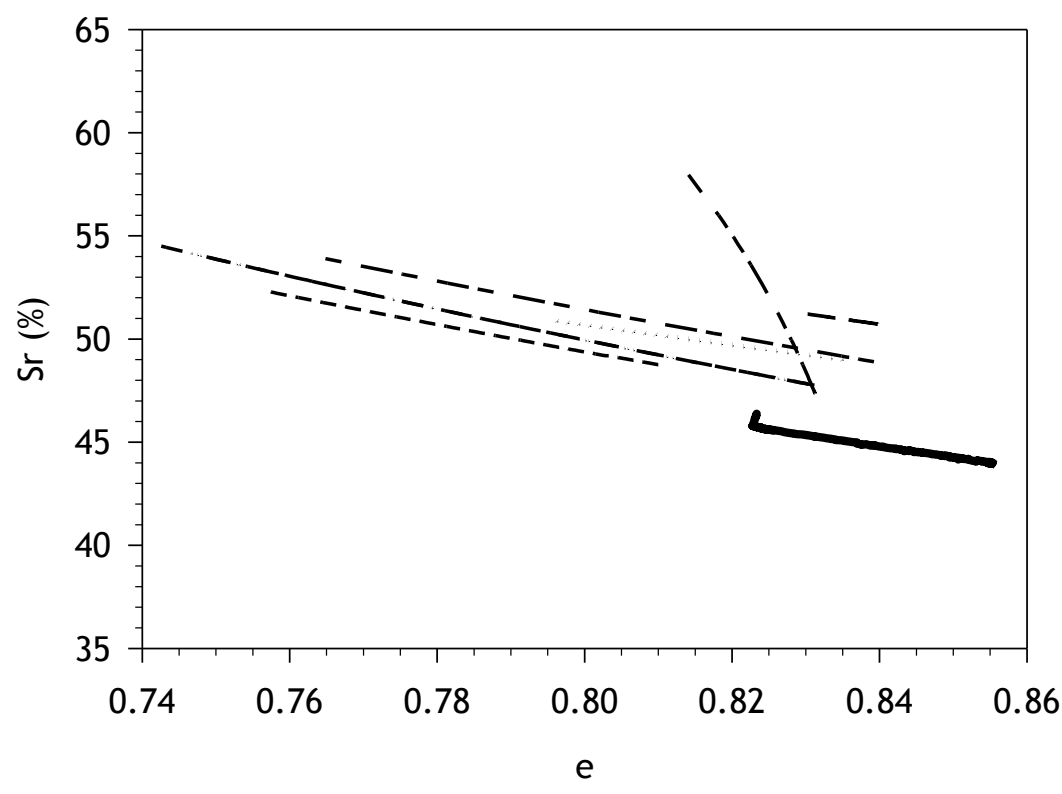

b) 


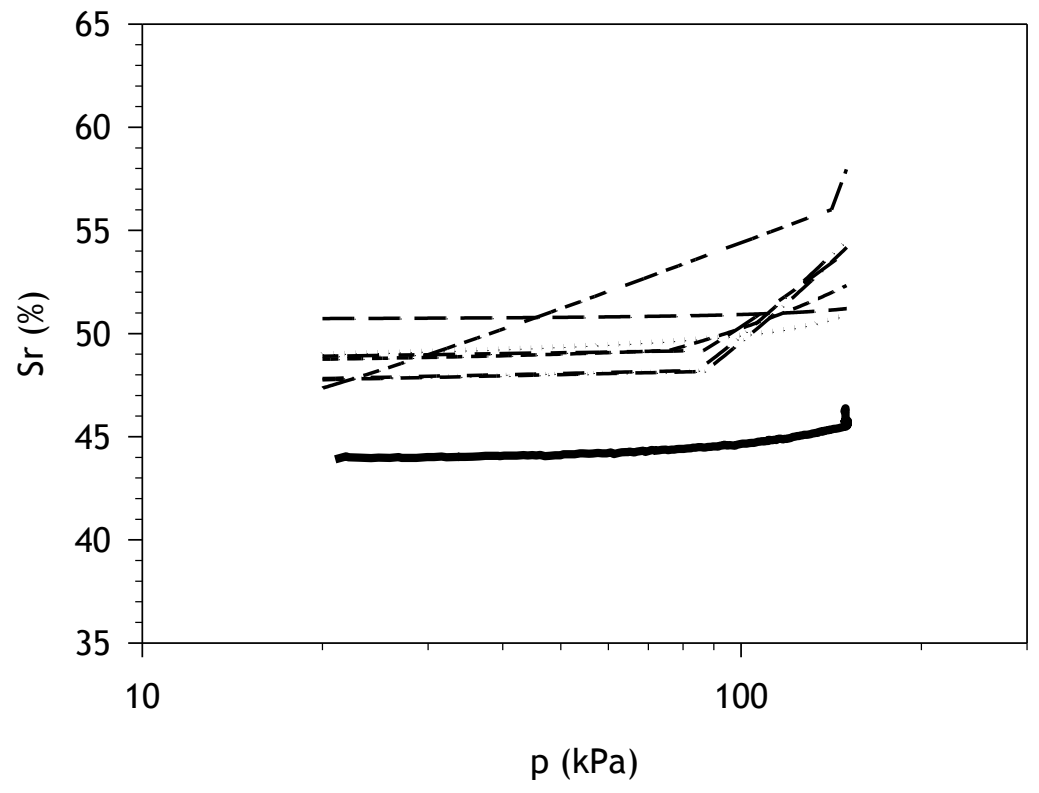

c)

Figure 9 - Predicted and experimental behaviour during loading stage of blind test: a) void ratio $(e)$ versus mean net stress $(p)$, b) degree of saturation $\left(S_{r}\right)$ versus void ratio $(e)$ and c) degree of saturation $\left(S_{r}\right)$ versus mean net stress $(p)$ 


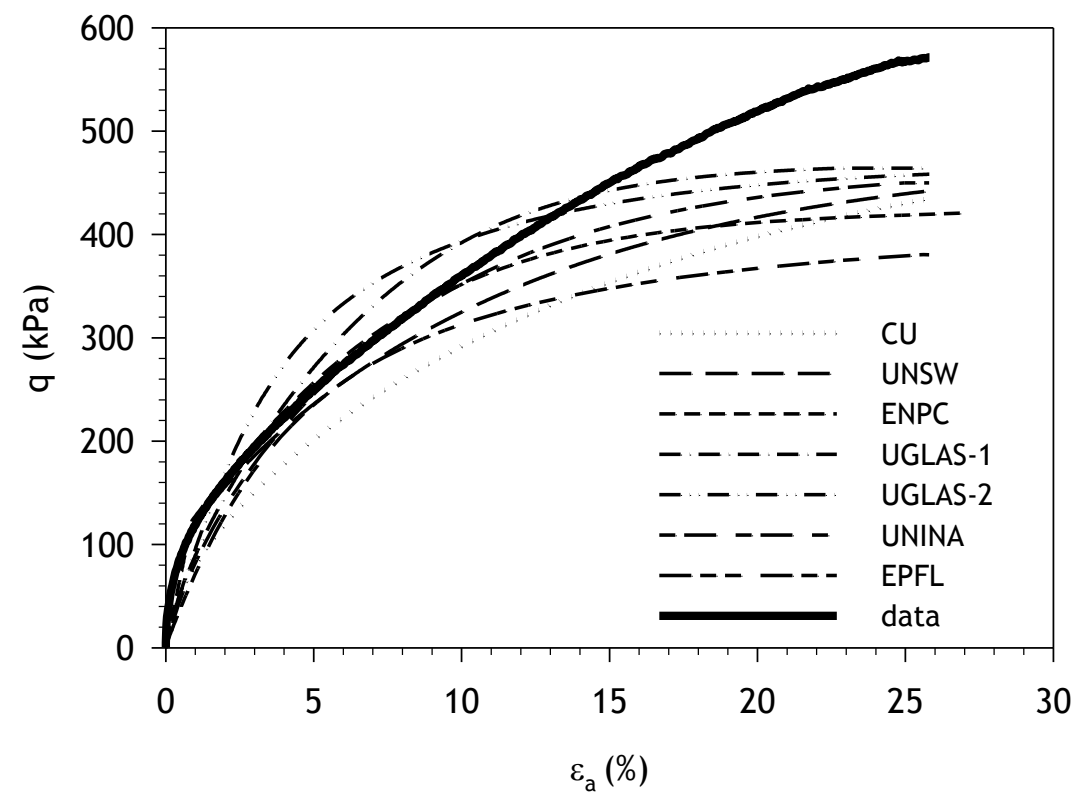

a)

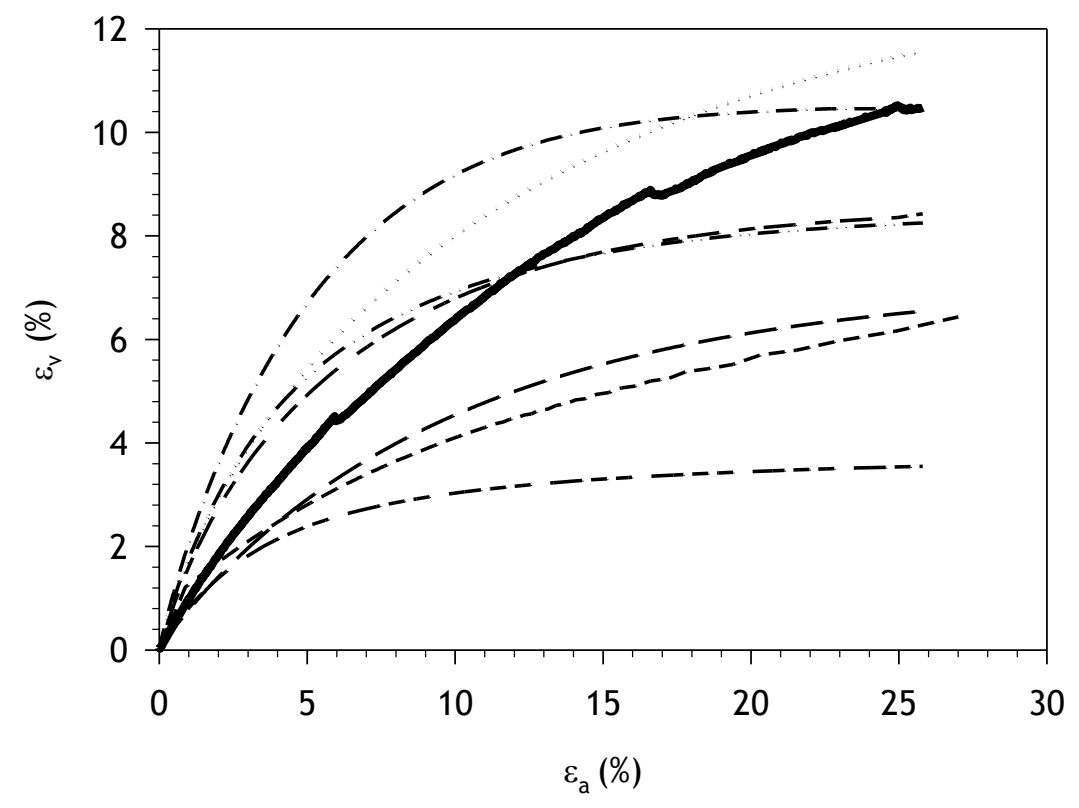

b) 

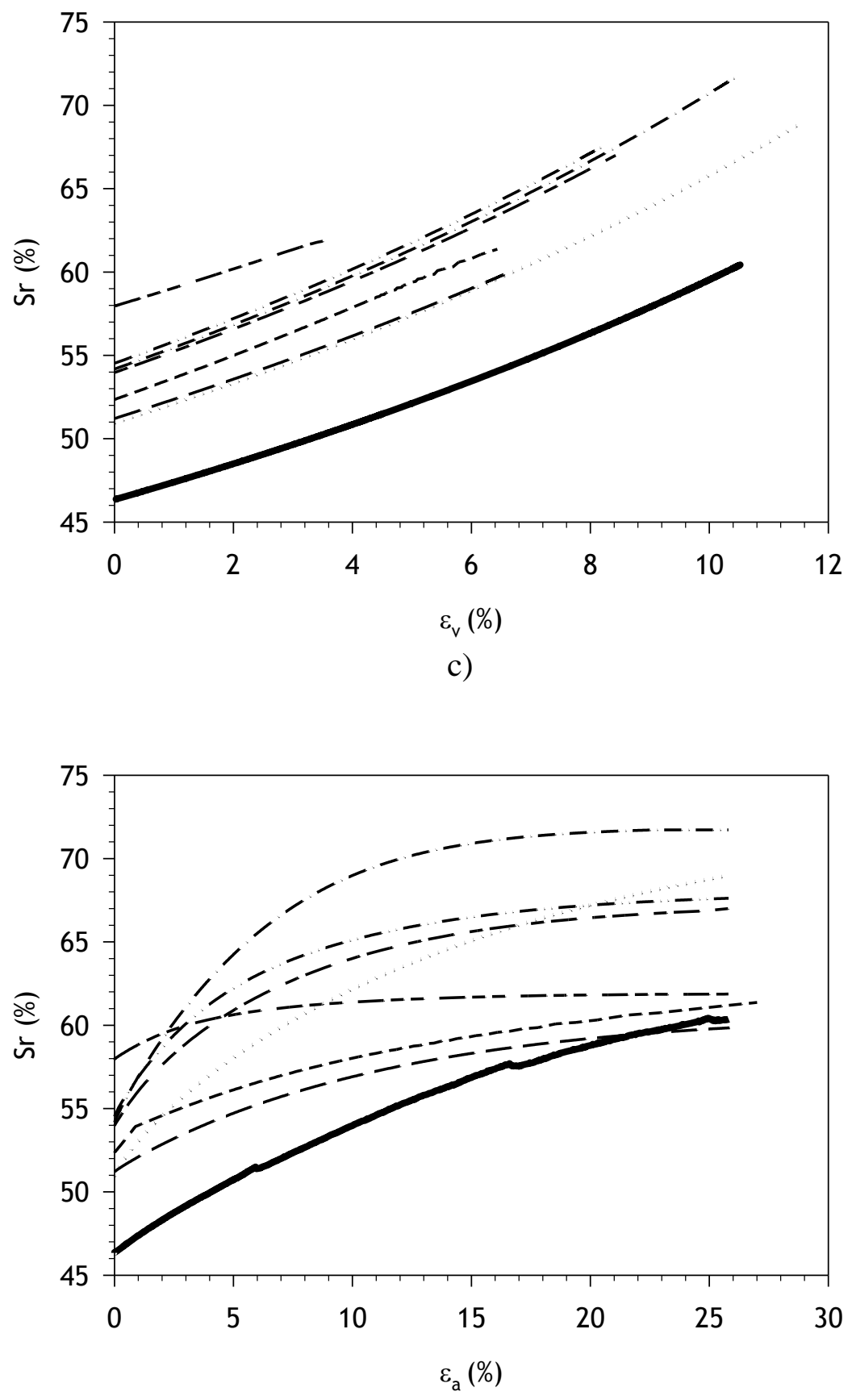

d) 


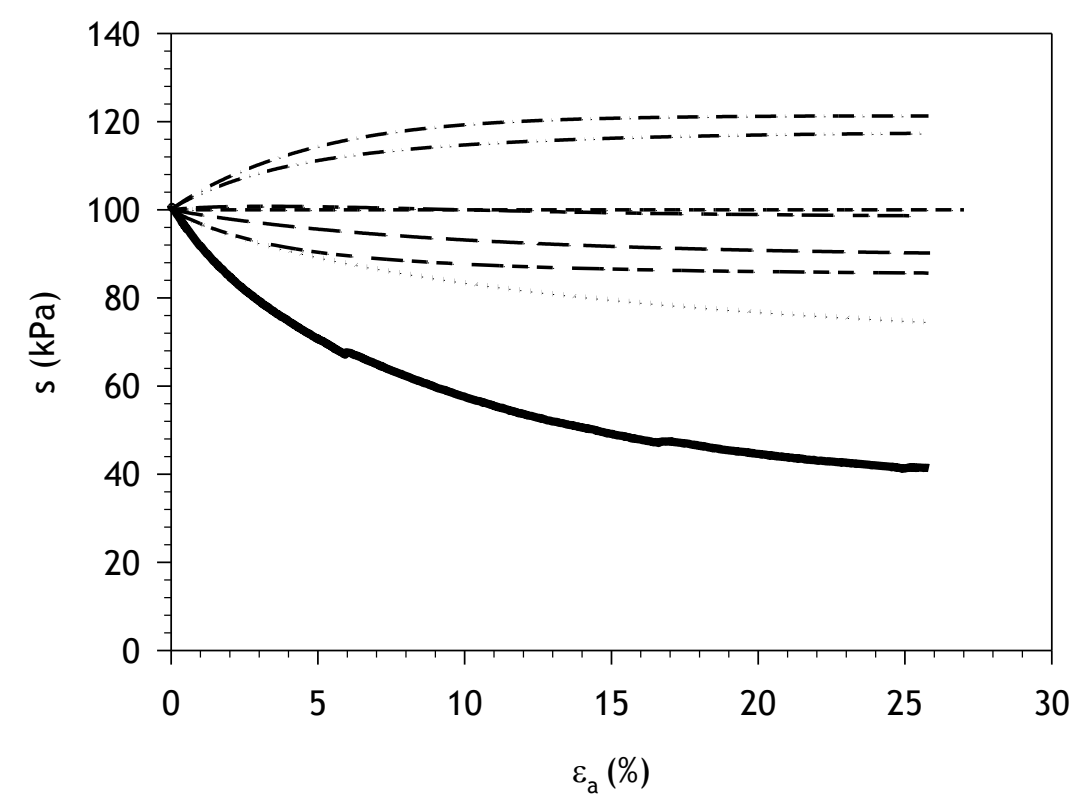

e)

Figure 10 - Predicted and experimental behaviour during shearing stage of blind test: a) deviator stress $(q)$ versus axial strain $\left(\varepsilon_{a}\right)$, b) volumetric strain $\left(\varepsilon_{v}\right)$ versus axial strain $\left(\varepsilon_{a}\right)$, c) degree of saturation $\left(S_{r}\right)$ versus volumetric strain $\left(\varepsilon_{v}\right)$, d) degree of saturation $\left(S_{r}\right)$ versus axial strain $\left(\varepsilon_{a}\right)$ and e) suction $(s)$ versus axial strain $\left(\varepsilon_{a}\right)$ 


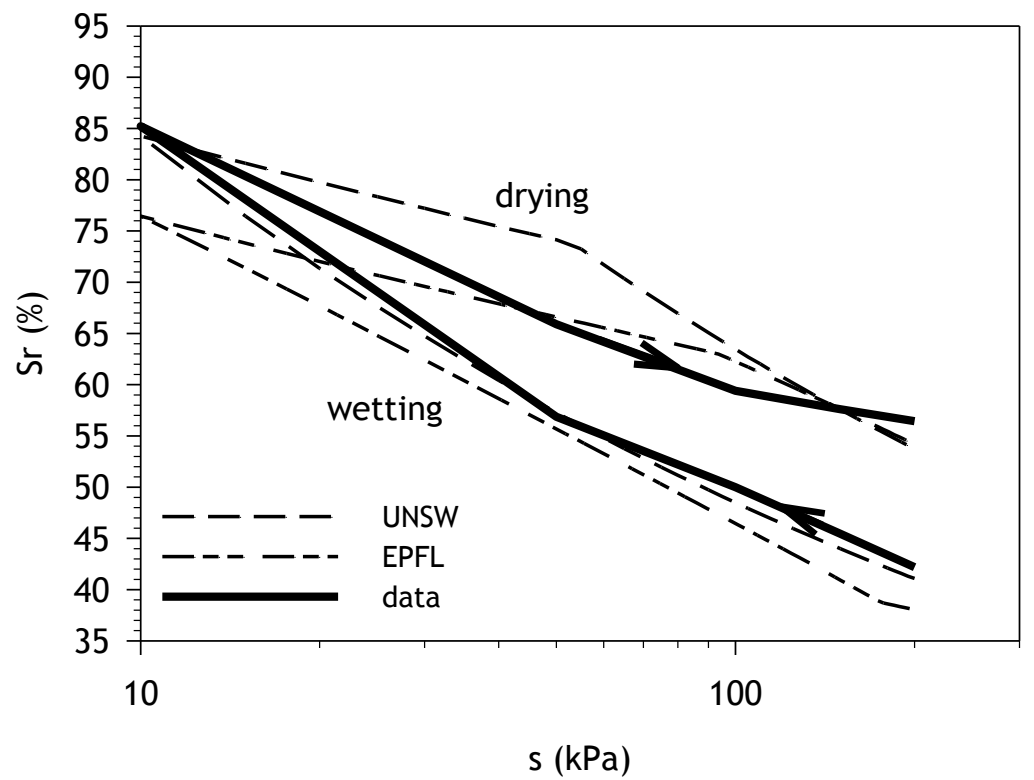

a)

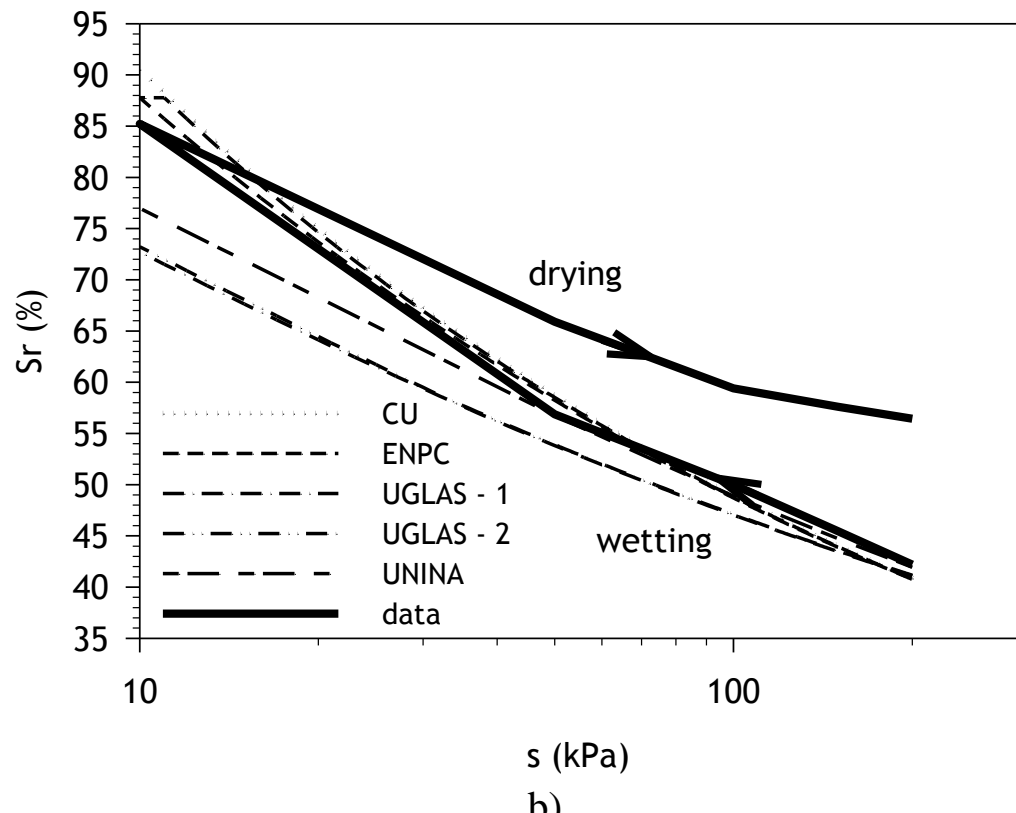

Figure 11 - Predicted and experimental behaviour during first wetting-drying cycle of test EDO-200: a) variation of degree of saturation $\left(S_{r}\right)$ versus suction $(s)$ for hysteretic water retention models (EPFL and UNSW) and b) variation of degree of saturation $\left(S_{r}\right)$ versus suction $(s)$ for non-hysteretic water retention models (CU, ENPC, UGLAS-1, UGLAS-2 and UNINA) 


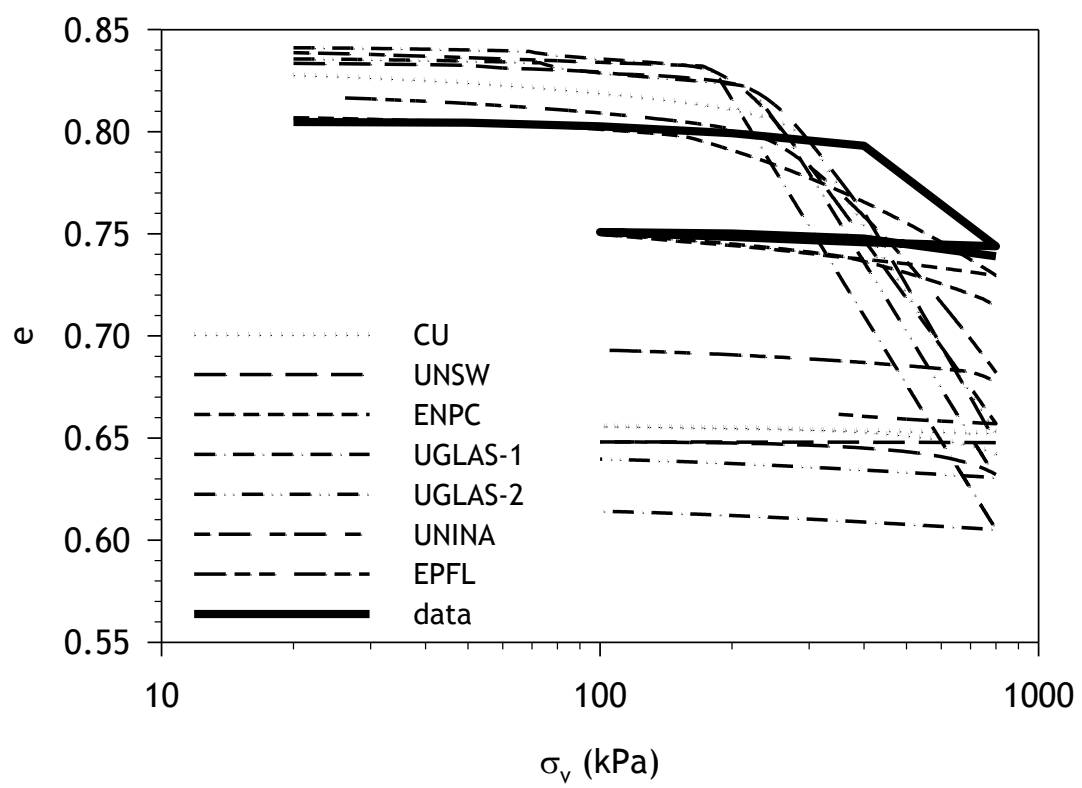

a)

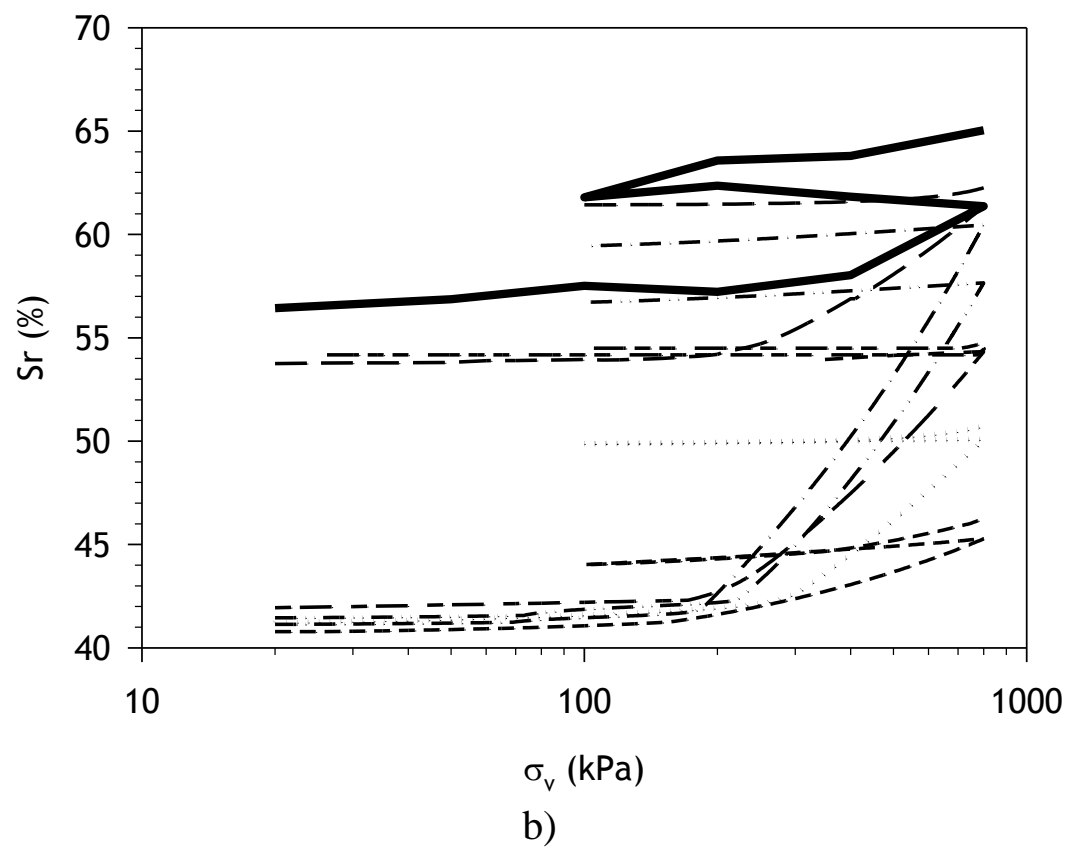

Figure 12 - Predicted and experimental behaviour during loading-unloading-reloading cycle of test EDO-200: a) variation of void ratio $(e)$ versus vertical net stress $\left(\sigma_{v}\right)$ and b) variation of degree of saturation $\left(S_{r}\right)$ versus vertical net stress $\left(\sigma_{v}\right)$ 


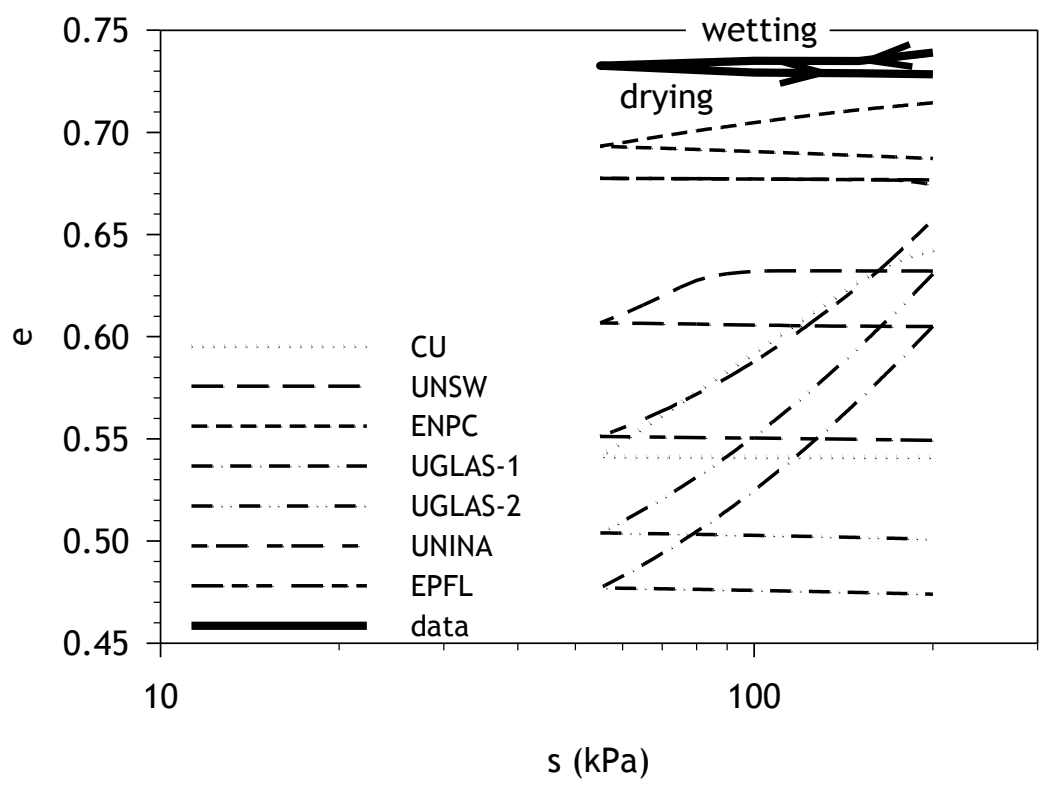

a)

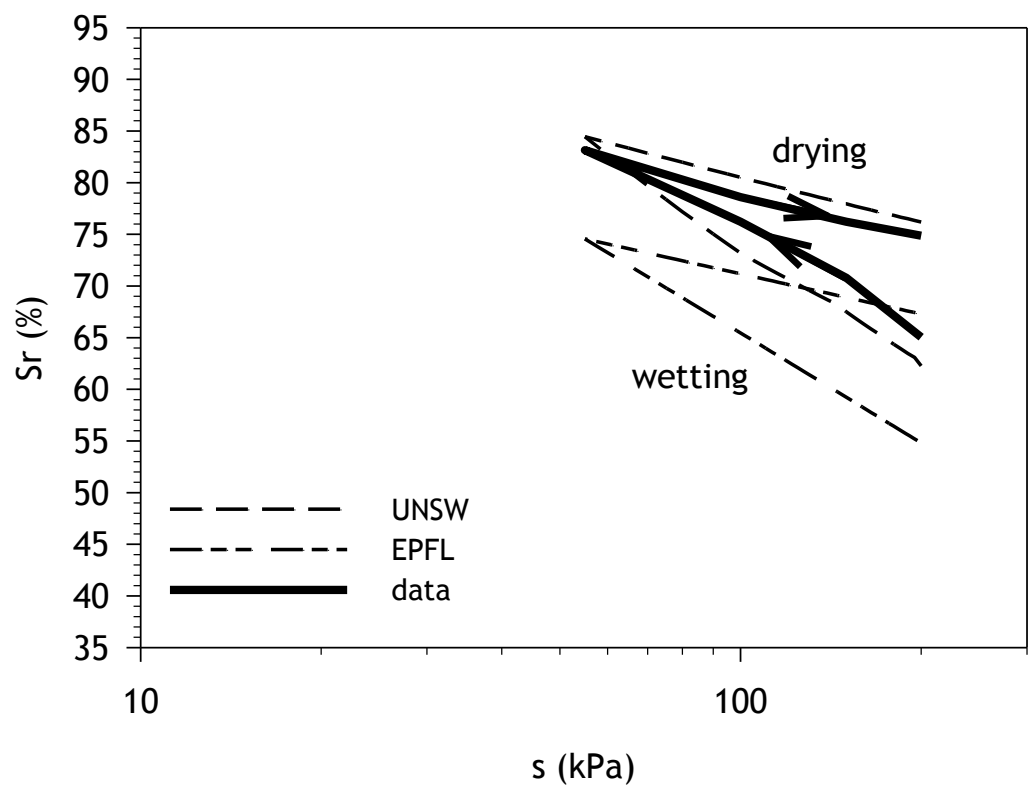

b) 


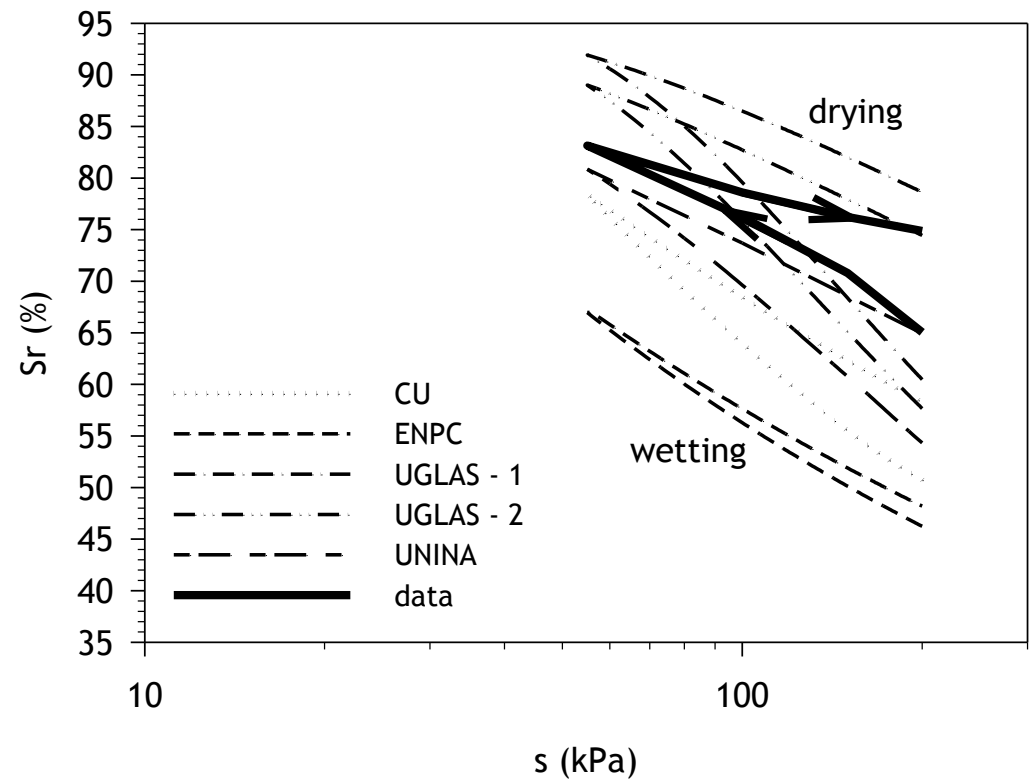

c)

Figure 13 - Predicted and experimental behaviour during second wetting-drying cycle of test EDO-200: a) variation of void ratio $(e)$ versus suction $(s)$, b) variation of degree of saturation $\left(S_{r}\right)$ versus suction $(s)$ for hysteretic water retention models (EPFL and UNSW) and c) variation of degree of saturation $\left(S_{r}\right)$ versus suction $(s)$ for non-hysteretic water retention models (CU, ENPC, UGLAS-1, UGLAS-2 and UNINA) 